\title{
CHILIDIOPSOIDEA (BRACHIOPODA) DEL DEVÓNICO INFERIOR DE LA PRECORDILLERA ARGENTINA
}

\author{
Zarela Angélica HERRERA', María José SALAS \\ y Javier A. GIOLITTI \\ CONICET, SEGEMAR (Delegación Córdoba). Av. Poeta Lugones 161 (5000) \\ Córdoba, Argentina. e-mail: mineria@si.cordoba.com.ar - Fax-tel: 54-51- \\ 244206. \\ 2 CONICET Cátedra de Estratigrafía y Geología Histórica, Facultad de Ciencias \\ Exactas, Físicas y Naturales, Universidad Nacional de Córdoba. Av. Vélez \\ Sarsfield 299, (5000) Córdoba. Argentina. \\ 3 Cátedra de Estratigrafía y Geología Histórica, Facultad de Ciencias Exactas, \\ Físicas y Naturales. Universidad Nacional de Córdoba. Av. Vélez Sarsfield \\ 299. (5000) Córdoba, Argentina.
}

Herrera, Z.A., Salas, M.J. y Giolitti, J.A. 1998. Chilidiopsoidea (Brachiopoda) del Devónico Inferior de la Precordillera Argentina. [Chilidiopsoidea (Brachiopoda) from the Lower Devonian, Argentine Precordillera]. Revista Española de Paleontología, 13 (2), 149-166. ISSN 0213-6937.

\begin{abstract}
Taxonomic analysis of numerous specimens of the genera Iridistrophia and Eoschuchertella recovered from the Talacasto Formation (Lower Devonian), Argentine Precordillera, allows for the description of five new species: Iridistrophia prima n. sp., I. dominans n. sp., I. aliciae n. sp., I. magna n. sp. and Eoschuchertella delicata n. sp. The first one of the mentioned taxa is restricted to the basal levels of the formation (Lochkovian), and the remainder forms are typical from the upper part of the studied sequence (Pragian-lower Emsian). These new records of Iridistrophia extent bring a particular information on the origin of Devonian brachiopods faunas from the Argentine Precordillera.
\end{abstract}

Keywords: Brachiopods, Chilidiopsoidea, Devonian, Argentine Precordillera, Systematics.

\section{RESUMEN}

El análisis taxonómico de numerosos ejemplares pertenecientes a los géneros Iridistrophia y Eoschuchertella, proveñientes de lá Forináción Tálááasto (Devónico Inferior) dio como resultado la identificación de cinco nuevas especies: Iridistrophia prima n. sp., I. dominans n. sp, I. aliciae n. sp, I. magna n. sp. y Eoschuchertella delicata n. sp. La primera de ellas está restringida a los niveles basales de la unidad (Lochkoviense), en tanto que las restantes son características de la parte superior de la secuencia (Praguiense - Emsiense inferior). Los nuevos hallazgos de Iridistrophia aportan información adicional acerca del origen de las faunas de braquiópodos devónicos en la Precordillera Argentina.

Palabras clave: Braquiópodos, Chilidiopsoidea, Devónico, Precordillera Argentina, Sistemática.

\section{INTRODUCCIÓN}

En la cuenca devónica de la Precordillera Argentina, la secuencia siliciclástica de la Formación Talacasto (Lochkoviense inferior - Emsiense inferior), presenta una abundante y diversificada fauna de braquiópodos. El estudio detallado de sus elementos realizado en estos últimos años ha permitido incorporar importante información para el análisis bioestratigráfico y paleobiogeográfico de esta cuenca (Giolitti, 1994; Herrera, 1991, 1993, 1995a,b; Racheboeuf y Herrera, 1994; Salas, 1995; Herrera y Racheboeuf, 1997).
El presente trabajo tiene por objeto realizar el análisis detallado de un taxón muy abundante en la secuencia devónica de la Formación Talacasto como lo es el género Iridistrophia, el cual está representado por cuatro especies, que caracterizan tanto a los niveles basales (Lochkoviense inferior) como superiores (Emsiense inferior) de esta formación.

La presencia y notable abundancia de este género en la Formación Talacasto (Precordillera Argentina) fue mencionada por Herrera (1991) quien lo identifica como una de las formas más características de la Biozona de Asociación C del Praguiense - Emsiense (Herrera,op. cit.; 


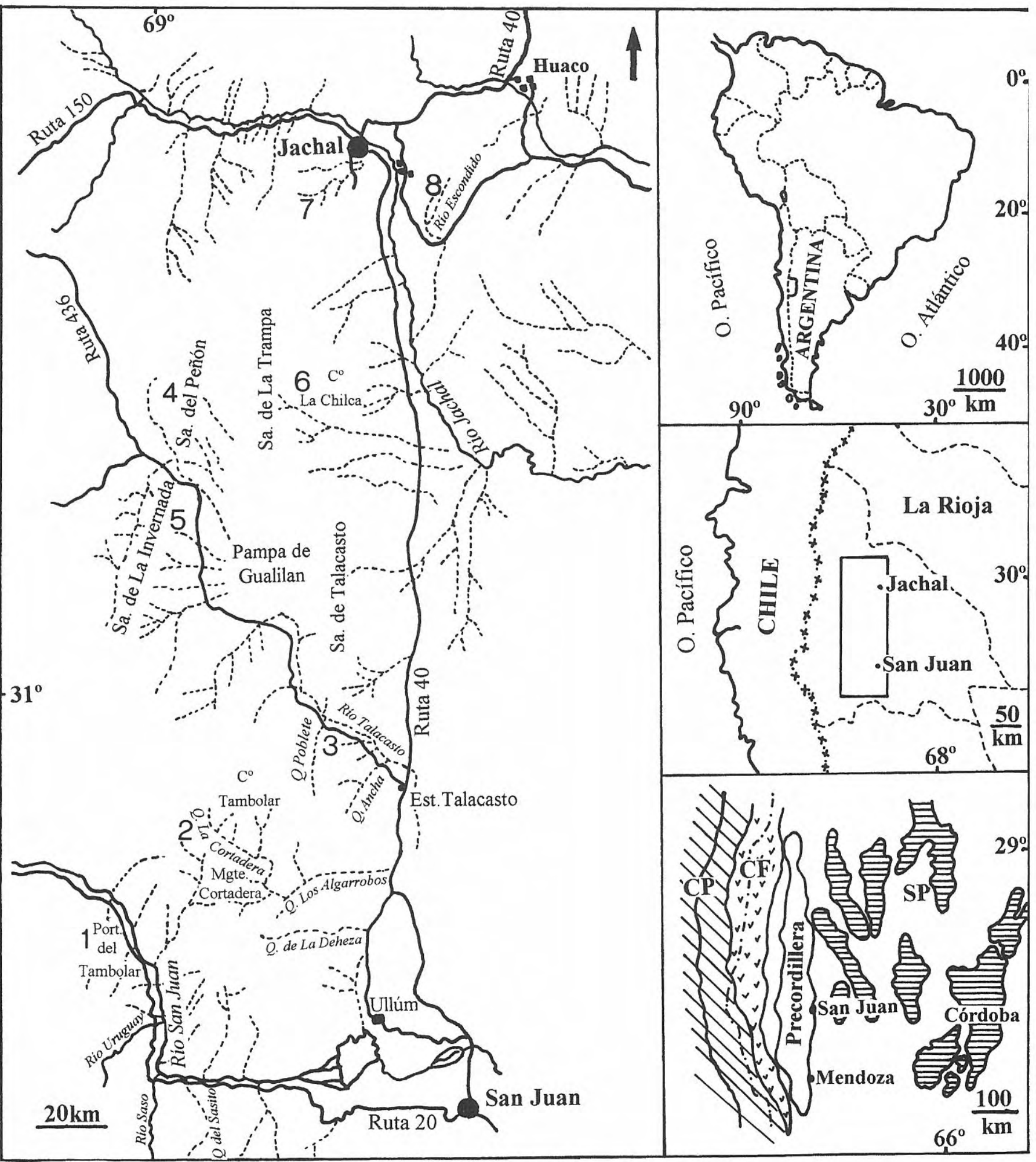

Figura1. Localización geográfica del área de estudio con las referencias de las secciones mencionadas en el texto. CP: cordillera Principal, CF: cordillera Frontal, SP: sierras Pampeanas. 1-Portezuelo del Tambolar, 2- quebrada de La Cortadera, 3- quebrada del río Talacasto, 4- cordón Agua del Peñón, 5- sierra de La Invernada, 6- cerro La Chilca, 7 loma de Los Piojos, 8- cerro del Fuerte.

1993; 1995a,b). Esta autora distinguió las especies, Iridistrophia sp. A e Iridistrophia sp. B, presentes, respectivamente, en las localidades de loma de Los Piojos y del cerro del Fuerte; e indicó la presencia de ejemplares asignables a este género en la localidad de Agua del Peñón. Hasta 1991 estos eran los únicos registros del género Iridistrophia en la Formación Talacasto, todos ellos referidos al Praguiense tardío - Emsiense. Con 


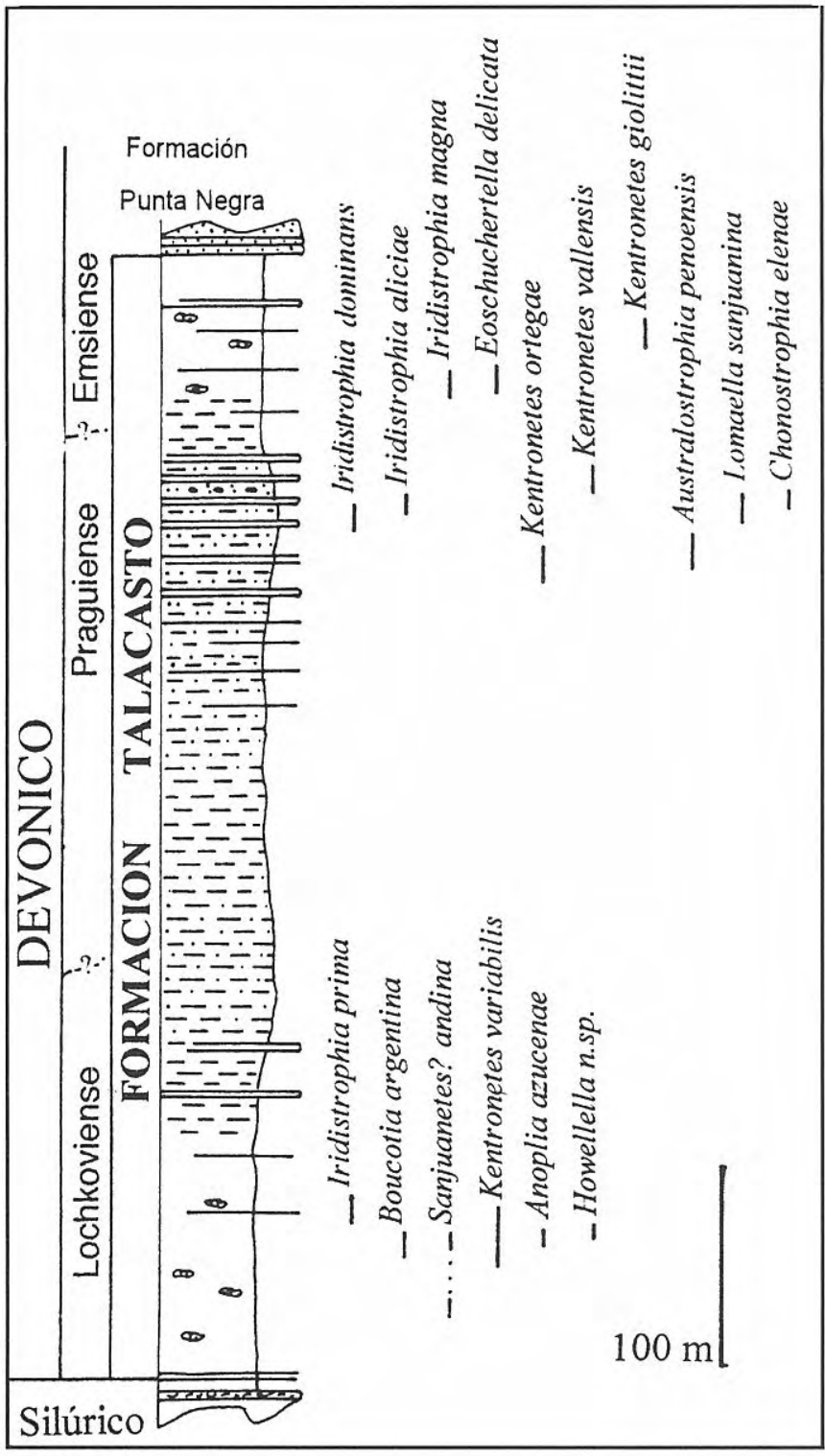

Figura 2. Sucesión litoestratigráfica sintética de la Formación Talacasto (utilizando principalmente como referencias las secuencias de loma de Los Piojos y cerro La Chilca), con la distribución de las especies del presente trabajo y las formas de braquiópodos más representativas de la formación.

posterioridad, la recolección de nuevo material fosilífero efectuada por M.J.S y Z.H., dio como resultado el hallazgo de representantes de este género en los niveles basales de la Formación Talacasto en las localidades de río Talacasto, quebrada La Cortadera y Portezuelo del Tambolar (Salas, 1995).

En esta contribución se da a conocer también el hallazgo de ejemplares del género Eoschuchertella Gratsianova, 1974 en los niveles superiores de la Formación Talacasto en la localidad de cerro la Chilca, a los que se designa como E. delicata n. sp.

El material de estudio fue recolectado en diferentes localidades de la cuenca devónica de la Precordillera, que de sur a norte son: Portezuelo del Tambolar, quebrada La Cortadera, quebrada del río Talacasto, cordón Agua del Peñón, sierra de La Invernada, cerro La Chilca, loma de Los Piojos y cerro del Fuerte (Fig. 1). La distribución estratigráfica de las especies reconocidas en este trabajo en la secuencia siliciclástica de la Formación Talacasto, se representa en la figura 2, junto a la presencia de otros taxones de braquiópodos - principalmente chonetoideos-, en una columna generalizada de la referida formación.

Los especímenes estudiados están depositados en el Museo de Paleontología de la Facultad de Ciencias Exactas, Físicas y Naturales de la Universidad de Córdoba, bajo las siglas CORD-PZ y CEGH-UNC.

Abreviaturas. L: largo; A: ancho; (v: valva ventral, d: valva dorsal); Aa: ángulo apical; Nc: número de costillas; Llám: largo láminas dentales; Alám: ángulo de las láminas dentales; Lcm: largo del campo muscular; Acm: ancho del campo muscular; Ab: ángulo de los braquióforos; valores promedios figurados en negrita, por ejemplo: L, A, L/A.

\section{PALEONTOLOGÍA SISTEMÁTICA}

\author{
Clase STROPHOMENATA Williams et al., 1996 \\ Orden STROPHOMENIDA Öpik, 1934 \\ Suborden ORTHOTETIDINA Waagen, 1884 \\ Superfamilia CHILIDIOPSOIDEA Boucot, 1959 \\ Familia Chilidiopsidae Boucot, 1959 \\ Subfamilia Chilidiopsinae Boucot, 1959
}

Género Iridistrophia Havlíček, 1965

Especie tipo: Orthis umbella Barrande, 1848.

\section{Observaciones}

El género Iridistrophia Havlíček, 1965, corresponde al material cuyos hallazgos habían sido referidos con anterioridad al género Schuchertella (siguiendo la asignación dada por Clarke, 1913) y posteriormente al género Schellwienella por numerosos geólogos y paleontólogos (Volkheimer, 1962; Castellaro,1966; Baldis, 1975, entre otros). Ambos géneros, Iridistrophia y Schellwienella, se diferencian (según Havlíček, 1967) por la presencia en Iridistrophia de láminas dentales largas y por la ausencia tanto de crestas limitando anteriormente el campo muscular como de seudopuntos.

Los caracteres morfológicos considerados por Havlíček (1967: p.193) para la diferenciación genérica entre Iridistrophia y Schellwienella han sido observados en nuestro material. En primer lugar, la presencia de láminas dentales largas y bien definidas, pudo observarse en un gran número de especímenes. Asimismo, se pudo reconocer que la región anterior del campo muscular ventral no presenta una cresta limitante, sino que el mismo está más o menos impreso según los estadios ontogenéticos. Igualmente se pudo constatar que los ejemplares carecen de seudopuntos. Por todo lo expuesto, 
hemos considerado apropiada la asignación del material precordillerano al género Iridistrophia Havlíček.

Por otra parte, es necesario destacar que para el estudio de las formas de Iridistrophia aqui consideradas se siguieron los criterios dados por Havlíček (1967) y aquellos propuestos por Williams y Brunton (1993) y Williams et al. (1996), en la clasificación de los braquiópodos ortotetidinos.

\section{Iridistrophia prima n. sp. Lám. I, figs. 1-6, 11-12}

Derivatio nominis: Del latín primus - $a$-um, la primera.

Holotipo: Molde interno de valva ventral CORD-PZ 9352 (Lám. I, fig. 4).

Localidad tipo: Quebrada La Cortadera, provincia de San Juan, Precordillera Argentina. Niveles inferiores de la Formación Talacasto.

\section{Material}

Moldes internos de valvas más o menos completas: 12 de valvas ventrales y 7 de valvas dorsales. Numerosos exteriores de ambas valvas.

\section{Distribución y edad}

Presente en las localidades de Portezuelo del Tambolar, quebradas La Cortadera y del río Talacasto. Lochkoviense inferior.

\section{Diagnosis}

Concha de tamaño pequeño a mediano (relación L/A de 0,62), más ancha que larga. Láminas dentales cortas,

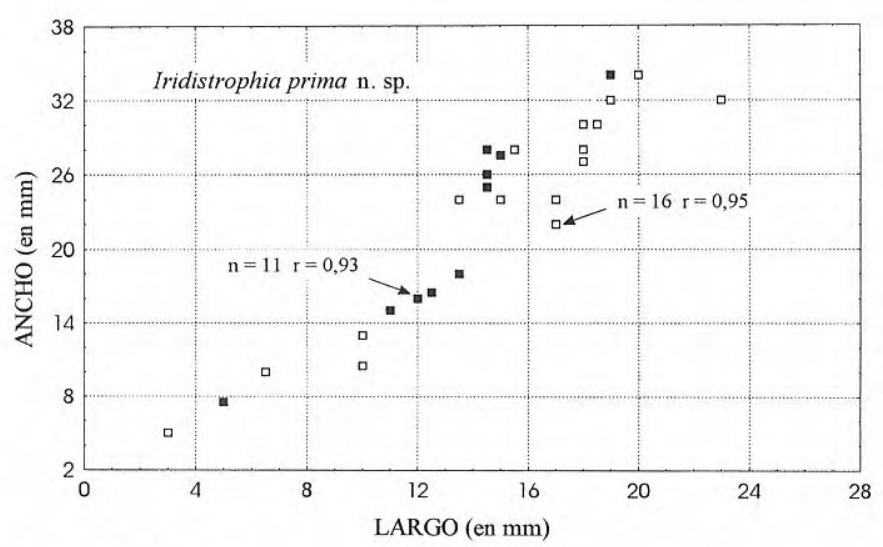

Figura 3. Diagrama de relación Largo/Ancho de la especie I. prima n. sp. Valvas dorsales, ㅁ valvas ventrales.

Llám promedio de $3 \mathrm{~mm}$, fuertemente divergentes (Alám promedio $103^{\circ}$ ). Campo muscular dorsal bien definido, limitado postero-lateralmente por una cresta delgada, ocupando una tercera parte de la longitud valvar.

Small to medium size shell $(L / W$ mean ratio $=0.62)$; wider than long. Dental plates are short, mean length is 3 $m$ m, strongly divergent $\left(103^{\circ}\right.$ mean). Dorsal muscular area well defined, postero-laterally bordered by a thin crest, and occupying the third part of the length.

\section{Descripción}

Concha de tamaño pequeño a mediano $(\mathbf{L}=15 \mathrm{~mm}, \mathbf{A}=24$ mm) (Fig. 3), de contorno semielíptico y perfil longitudinal convexo-plano; línea cardinal recta. Ancho máximo coincidente con la línea cardinal o situado en el cuarto posterior valvar. Valva ventral plana, con umbón levemente

\section{Lámina I}

1-6, 11-12 Iridistrophia prima n. sp. 1, exterior ventral, CORD-PZ 9369 (x 0,8). 2, exterior ventral, vista parcial del interior ventral con láminas dentales, CORD-PZ 9370 (x 1). 3, exterior dorsal, CORD-PZ 6371 (x1,2). 4, molde interno ventral, Holotipo CORD-PZ 9352 (x 1,2). 5, 6, moldes internos ventrales CORD-PZ 9372 (x 1), CORD-PZ 9373 (x 0,8). 11, 12. moldes internos dorsales CORD-PZ 9374, 9375 (x 1).

7-10, 13-29 Iridistrophia dominans n. sp. 7, 8, vistas ventral y dorsal del mismo ejemplar CORD-PZ 9376 (x1). 9, molde externo dorsal, incompleto, CORD-PZ 9377 (x 1). 10, interior ventral, incompleto, CORD-PZ 9378 (x 1,2). 13, 18, molde interno del mismo ejemplar, vistas ventral y dorsal, CORD-PZ 9379. (x 1). 14 , molde interno ventral, CORD-PZ 9380 (x 1,2). 15, molde interno ventral, vista parcial de molde externo dorsal de ejemplar adulto CORD-PZ 9381 (x1). 16, molde interno ventral, Holotipo, CEGH-UNC 2529 (x 1). 17, molde interno ventral CORD-PZ 9382 (x 1,5). 19, interior ventral, réplica en látex CORD-PZ
9383 (x0,5). 20, molde interno dorsal CORD-PZ 9390 (x 0,8). 21, 22. molde interno dorsal y réplica en látex CORD-PZ 9384 (x 0,8). 23, molde interno dorsal CORD-PZ 9385 (x 1,5). 24,25, moldes internos dorsales y réplica en látex CORD-PZ 9386 (x 0,8). 26, látex interior dorsal CORD-PZ 9387 (x 1). 27, 28, látex de ejemplares articulados, vista dorsal CORD-PZ 9388, 9389 (x 1). 29, molde interno dorsal, Paratipo, CEGUN-UNC 2530 (x 0,8).

30-38 Iridistrophia aliciae n. sp. 30, 31, réplicas en látex de exterior ventral y dorsal CORD-PZ 9391, 9392 (x 0,5). 32, molde interno ventral, Holotipo, CEGH-UNC 2575 (x 1). 33, molde interno ventral CORD-PZ 9393 (x 1). 34, molde interno dorsal, Paratipo, CEGH-UNC 2576 ( $x$ 1). 35, 36. molde interno dorsal incompleto y réplica en látex del proceso cardinal CORD-PZ 9394 (x 1) (x 1,5). 37, 38, interiores dorsales, réplicas en látex, CORD-PZ 9395, 9396 (x 1).

39-42 Iridistrophia magna n. sp. 39, réplica en látex de un exterior ventral, CORD-PZ 9369 (x0,8). 40 - 42, moldes internos ventrales, CORD-PZ 9370, 9371, 9372 (x1). 
Lámina I
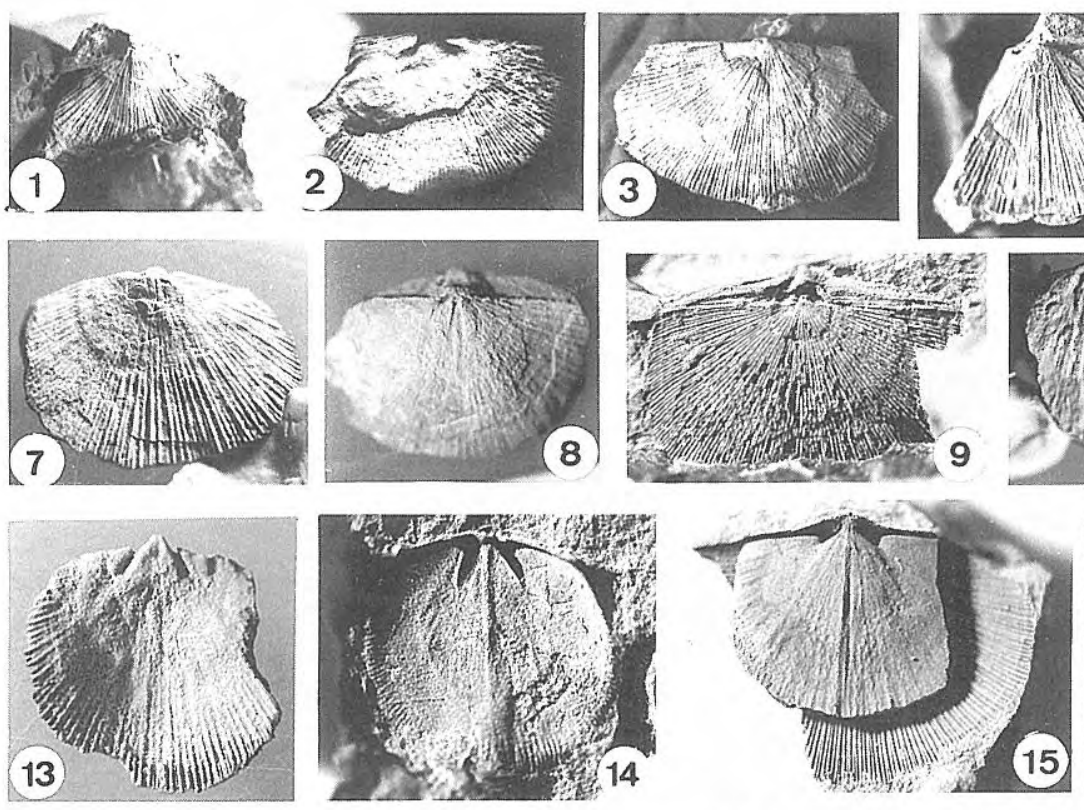

(15)

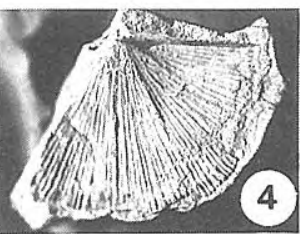

(4)
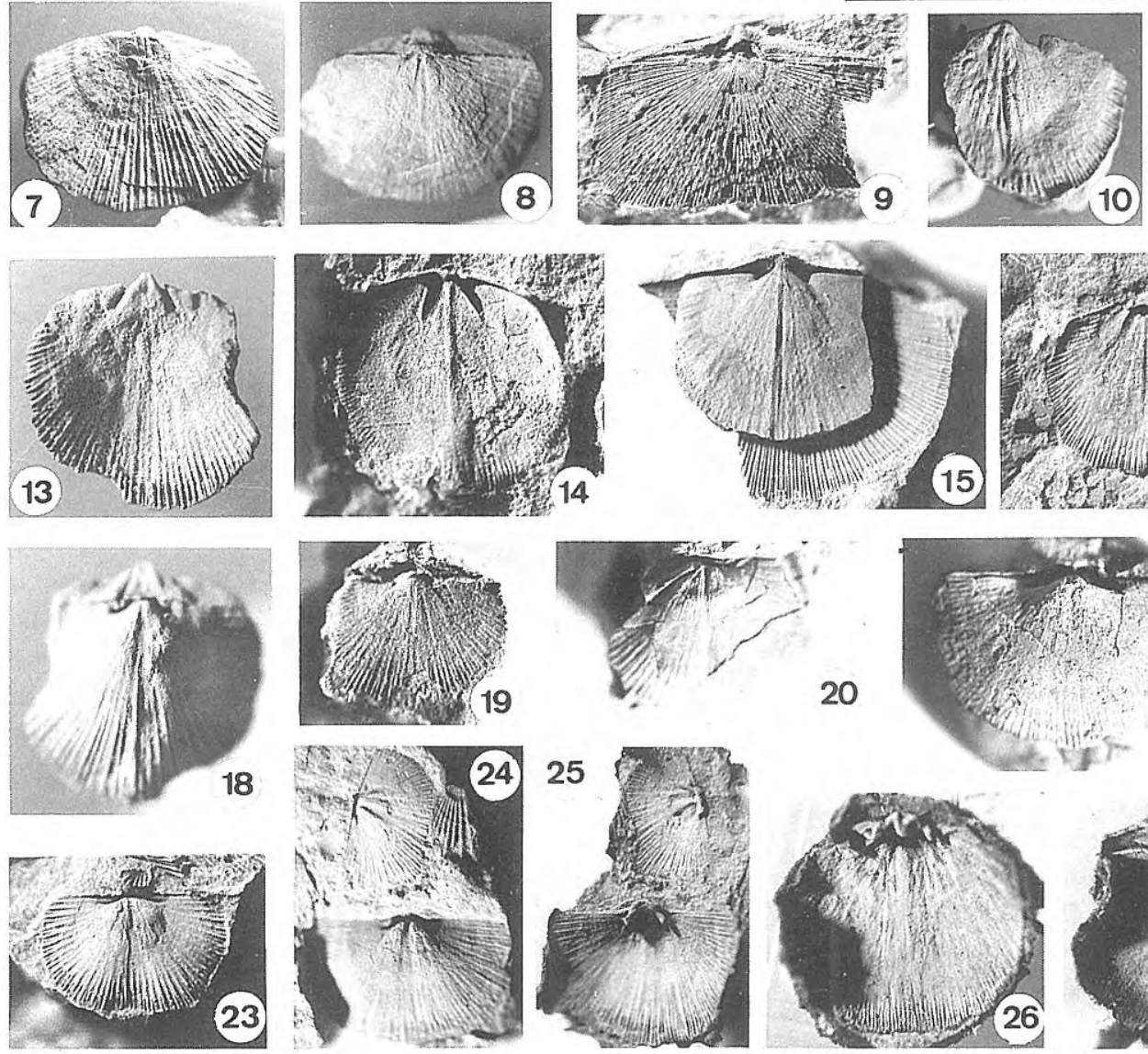

20
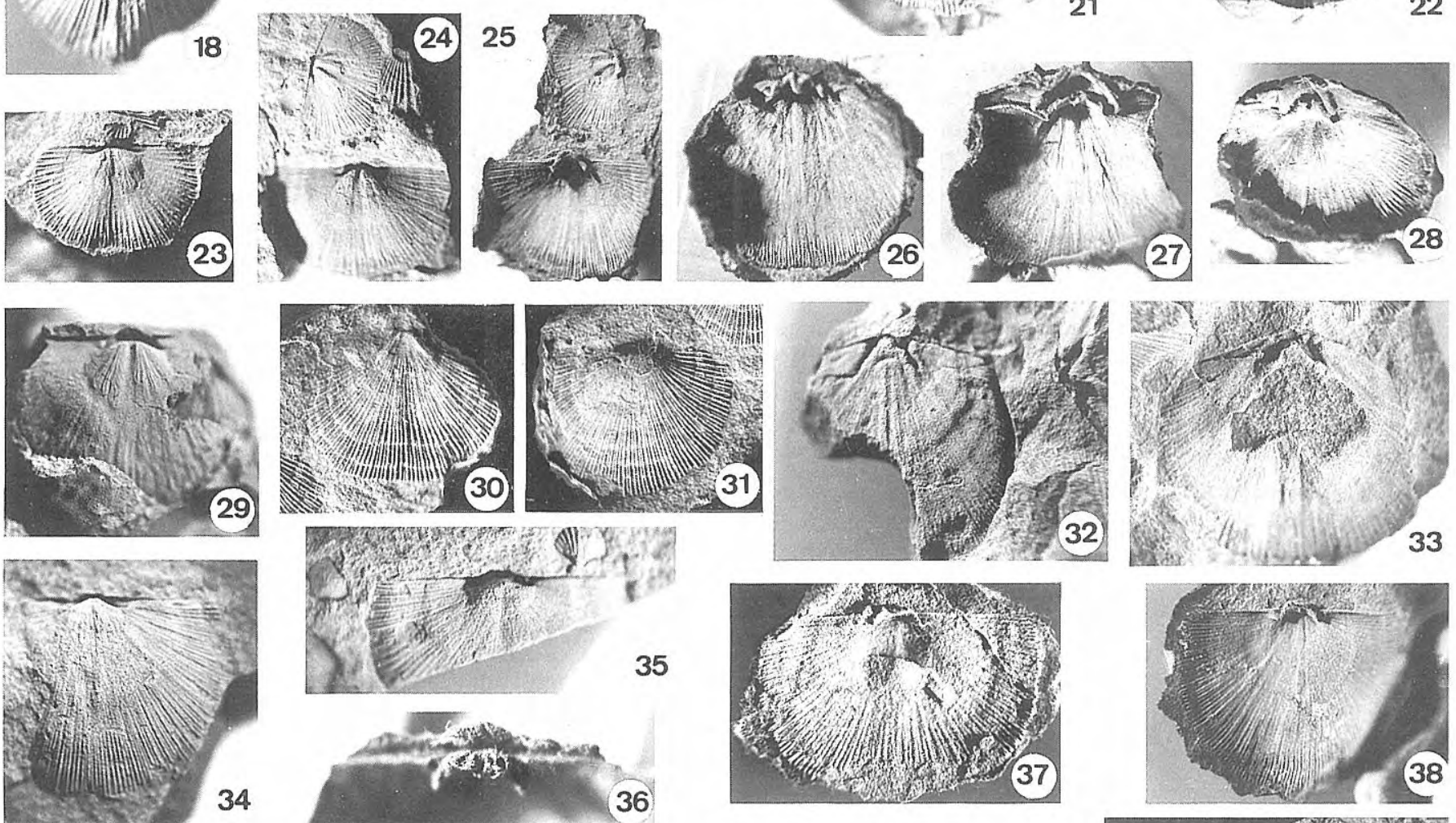

35
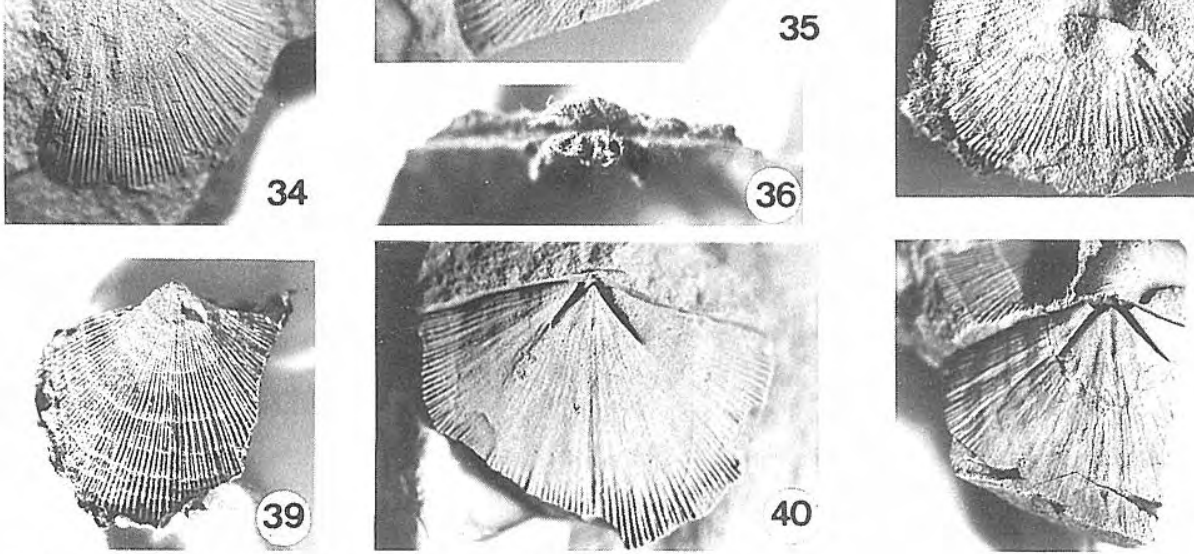

41

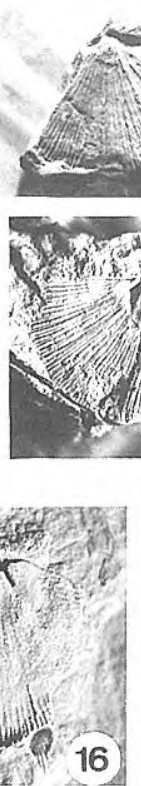

(11) 12

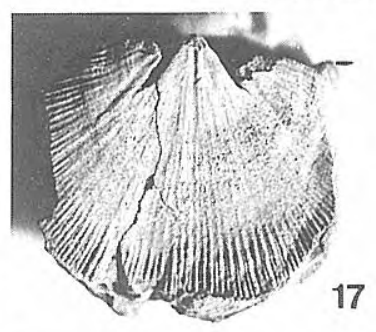

17
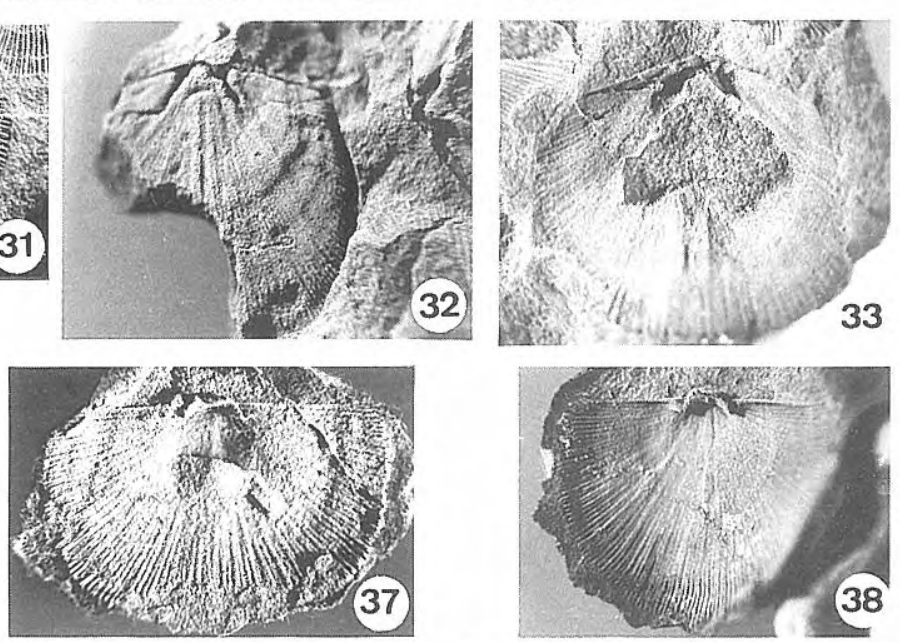

Revista Española de Paleontología, 13 (2), 1998. 
sobreelevado, algo resupinada. Interárea apsaclina, alta y de superficie plana, ángulo apical promedio de $159^{\circ}$. Deltirio cubierto por seudodeltidio convexo. Valva dorsal levemente más convexa en la mitad posterior. Umbón poco prominente. Interárea anaclina, nototirio parcialmente cubierto por placas quilidiales muy reducidas. Ornamentación compuesta por finas costillas radiales, cuyo número se incrementa por intercalación, y de sección transversal y angulosa, separadas por espacios intercostales más anchos y de sección redondeada. En el borde anterior se observan entre 5 y 6 costillas en $2 \mathrm{~mm}$, llegando en un caso a 7. La microornamentación está representada por líneas de crecimiento visibles en los espacios intercostales.

Interior de la valva ventral con dientes redondeados y robustos. Láminas dentales cortas, Llám promedio de $3 \mathrm{~mm}$ y divergentes según un ángulo de $103^{\circ}$, incipientes en algunos ejemplares, mientras que en los individuos adultos se encuentran bien desarrolladas. Campo muscular débilmente impreso en la mayoría de los especímenes; no se diferencian impresiones de aductores y diductores. Superficie interna de la valva con fuerte reflejo de la ornamentación externa.

Interior de valva dorsal con proceso cardinal prominente, bilobulado con un surco medio longitudinal en cada lóbulo. Dichos lóbulos son convergentes hacia el fondo de la valva, inclinados postero-ventralmente, sostenidos por una cresta que es más corta en las formas juveniles, y separados longitudinalmente por un surco estrecho. Las crestas limitantes de las fosetas son gruesas y prominentes, hacia la parte posterior se funden al proceso cardinal, mientras que hacia adelante se prolongan en un par de braquióforos. Braquióforos poco desarrollados, cortos, levemente cóncavos (hacia la línea media) que divergen en un ángulo aproximado de $90^{\circ}$. Las fosetas dentales son de contorno triangular y poco profundas, paralelas a la línea cardinal. Septo medio grueso y de sección transversal redondeada, extendido aproximadamente $1 / 6$ de la longitud valvar. Campo muscular bien delimitado; impresiones de los aductores anteriores y posteriores débilmente marcadas, limitadas en su margen postero-lateral por delgadas crestas y alcanzando una tercera parte de la longitud de la valva. Superficie interna de la valva con reflejo de la ornamentación externa.

\section{Comparación}

Los ejemplares aquí descritos difieren de la especie $I$. umbella (Barrande, 1848) (en Havlíček, 1967: pág. 194, lám. 41 y 42, figs. 7-16 y 3, 5, 8) en el contorno menos transverso de las valvas (en I. umbella $\mathbf{A}=29,3 \mathrm{~mm}, \mathbf{L}=$ $16,8 \mathrm{~mm}$ ); mayor número de costillas (en $I$. prima n. sp., 12 en $5 \mathrm{~mm}$, mientras que en $I$. umbella, el número de costillas en $5 \mathrm{~mm}$ es de 6 a 8); menor longitud y mayor ángulo de divergencia de las láminas dentales: en I. prima n. sp. la longitud de las láminas dentales (promedio) es de $3 \mathrm{~mm}$ con una divergencia promedio de $103^{\circ}$ mientras que en $I$. umbella las láminas dentales alcanzan 8 a $9 \mathrm{~mm}$ de longitud y divergen $70^{\circ}$ a $80^{\circ}$. Por último, I. prima $\mathrm{n}$. sp. presenta un campo muscular dorsal definido y limitado postero-lateralmente por elevaciones, mientras que en I. umbella el mismo es indiferenciado.

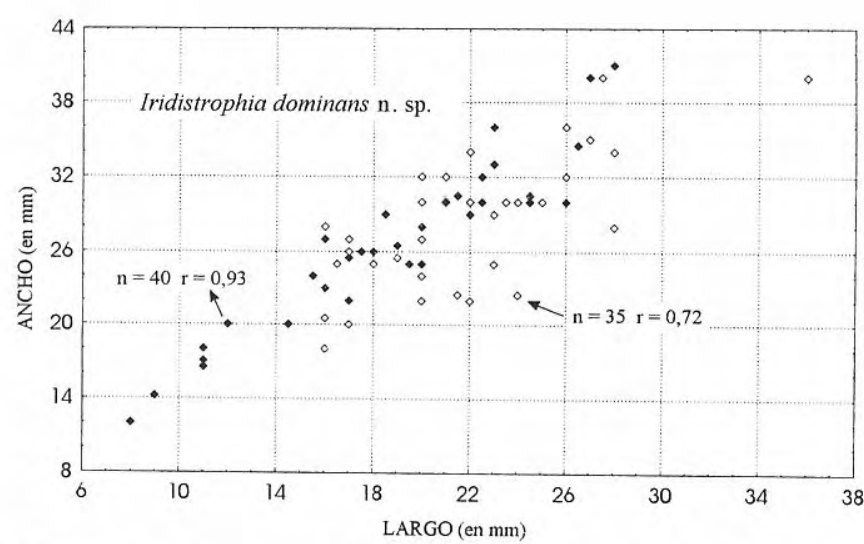

Figura 4. Diagrama de relación Largo/Ancho de la especie

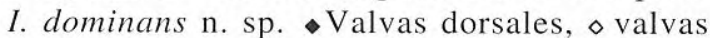
ventrales.

Asimismo, los ejemplares de $I$. prima n. sp. se diferencian de I. iris (Barrande, 1879) (en Havlíček, 1967: pág. 194, lám. 42, figs. 5-8, 13) en el mayor número de costillas y en la forma más angulosa de las mismas. En comparación con I. elongata (Barrande, 1879) (en Havlíček, 1967: pág. 195, lám. 42, fig. 1), los especímenes estudiados difieren en su contorno más transverso y en la forma y disposición de las costillas: en I. elongata los espacios intercostales entre dos costillas más acentuadas están ocupados por 3 a 6 costillas más finas, mientras que en I. prima n. sp. el patrón es más regular.

En cuanto a I. eodevonica Havlíček (1967: pág. 195, lám. 45, figs. 9-12, 16) difiere de I. prima n. sp. en su mayor tamaño, perfil longitudinal biconvexo, menor número de costillas y mayor longitud de las láminas dentales. Es necesario señalar que la ausencia de descripciones de los caracteres morfológicos internos en las especies del Lochkoviense - Praguiense de Bohemia, mencionadas por Havlícek (1967) impide una comparación más detallada con los ejemplares hallados en los niveles basales de la Formación Talacasto.

Respecto a las especies mencionadas por Smith (1980) para el Lochkoviense de las islas del Canadá Artico, I. prima n. sp. difiere de I. johnsoni Smith, 1980 (pág. 43, lám. 12, figs. 9, 10, 13-35; lám. 13, figs. 1-21) en el contorno de las valvas; en la posición del ancho máximo (ubicado en la mitad de L en I. johnsoni, mientras que en $I$. prima n. sp. el ancho máximo es coincidente con la línea cardinal o ligeramente desplazado hacia delante); en la forma y disposición de las costillas -las cuales en I. johnsoni son de sección transversal redondeada y se curvan progresivamente hacia el margen postero lateral- y por último, I. prima $\mathrm{n}$. sp. varía en el menor ángulo de divergencia de las láminas dentales y en la forma del proceso cardinal.

Del mismo modo, I. prima n. sp. se diferencia de $I$. thorsteinssoni Smith (1980: pág. 43, lám. 14, fig. 1-12, $14,15,18,22,27)$ en el menor desarrollo de las láminas dentales, la presencia de una cresta entre los lóbulos del proceso cardinal y de elevaciones posterolaterales limitando el campo muscular dorsal. 
Con respecto a la especie I. dendritica Benedetto, 1984 (pág. 52, lám. 8, figs. 8-17; lám. 9, figs. 1-6), proveniente de la sierra de Perijá, Venezuela y asignada a una edad Emsiense - Eifeliense. La especie hallada en la base de la Formación Talacasto difiere tanto en el contorno más transverso de las conchas y en el mayor número de costillas, como en la menor longitud de las láminas dentales, el campo muscular ventral indiferenciable y la menor longitud del septo medio dorsal.

Los ejemplares descritos difieren de las restantes especies halladas en la Precordillera principalmente en el contorno más transverso de las valvas; el mayor ángulo apical; la menor longitud y mayor divergencia de las láminas dentales.

\section{Iridistrophia dominans $\mathrm{n} . \mathrm{sp}$.} Lám. I, figs. 7-10, 13-29

v. 1991 Iridistrophia sp. A, Herrera, 62-68, lám. 10, figs. 112; lám.11, figs.1-10; lám.12, figs.1-2.

Derivatio nominis: Del latin dominans-antis, que domina, en alusión a su predominio en los niveles superiores de la Formación Talacasto, en la localidad de loma de Los Piojos.

Holotipo: Molde interno de valva ventral CEGH-UNC 2529 (Lám. I, fig.16).

Paratipo: Molde interno de valva dorsal CEGH-UNC 2530 (Lám. I, fig. 29).

Localidad tipo: Sección de loma de Los Piojos, provincia de San Juan, Precordillera Argentina. Niveles superiores de la Formación Talacasto.

\section{Material}

Moldes internos de valvas más o menos completas: 30 de valvas ventrales y 36 de valvas dorsales. Numerosos exteriores de ambas valvas.

\section{Distribución y edad}

Presente en las localidades de la quebrada del río Talacasto y loma de Los Piojos, edad Praguiense superior a Emsiense.

\section{Diagnosis}

Concha de tamaño mediano y contorno subcircular a semielíptico (L/A de 0,79), con un ángulo apical promedio de $155^{\circ}$. Láminas dentales con una longitud promedio de $3,4 \mathrm{~mm}$ y divergentes con un ángulo promedio de $81^{\circ}$. Campos musculares ventral y dorsal bien impresos.

Medium size shell $(L / W$ mean ratio $=0.79)$ and subcircular to subelliptic outline, with an apical mean angle of $155^{\circ}$. Dental plates mean lenght is 3,4 mm, and diverge with a mean angle of $81^{\circ}$. Ventral and dorsal muscular areas well imprimed.

\section{Descripción}

Concha de tamaño mediano $(\mathbf{L}=21,7 \mathrm{~mm}, \mathbf{A}=27,4$ $\mathrm{mm}$ ), de contorno semicircular a semielíptico (Fig. 4). Perfil longitudinal convexo-cóncavo a convexo-plano, moderadamente resupinado. Línea cardinal recta con extremidades cardinales obtusas. Ancho máximo observado de $40 \mathrm{~mm}$. Valva ventral plana a ligeramente resupinada. Umbón aguzado y elevado. Interárea plana, cataclina a ligeramente apsaclina, cuya altura varía entre un tercio y un cuarto de la longitud de la valva. Deltirio cubierto totalmente por el seudodeltidio. Valva dorsal moderadamente convexa, con la mayor convexidad localizada en la región posteromedia de la valva. Umbón dorsal pequeño a inconspicuo. Interárea dorsal muy baja, un tercio de la ventral a inexistente. Ornamentación constituida por costillas radiales delgadas, angulosas, con interespacios ligeramente redondeados en sección. El incremento del número de costillas es por intercalación. En la región anterior de las valvas se observan 6 a 7 costillas en 2 milímetros. Líneas de crecimiento espaciadas.

Interior de valva ventral con dientes pequeños, soportados por láminas dentales delgadas con un Llám promedio de $3,4 \mathrm{~mm}$, divergentes según un ángulo promedio de $81^{\circ}$ y parcial o totalmente obliteradas por depósitos secundarios en especímenes gerónticos. Campo muscular grande, de contorno subtriangular, extendiéndose -en general- algo por delante de la mitad de la longitud valvar. Lcm máximo observado de $12,7 \mathrm{~mm}$. Postero-lateralmente está limitado por prolongaciones tenues de las láminas dentales, no observables en los especímenes adultos. Impresiones de los músculos aductores pequeñas, subovales, ubicadas en la mitad posterior del campo y muy marcadas. Impresiones de los músculos diductores débilmente conservadas, recorridas longitudinalmente por una serie de estrías muy delgadas con el margen anterior levemente flabelado. Miofragma delgado, dividiendo longitudinalmente al campo muscular. Crenulación periférica muy acentuada.

Interior dorsal con fosetas dentales profundas y pequeñas, excavadas en depósitos del fondo de la valva y limitadas por rebordes internos gruesos. Estos se prolongan hacia adelante en un par de braquióforos y hacia atrás se unen con la base del proceso cardinal. Bases de los braquióforos robustas y divergentes según un ángulo promedio de $83^{\circ}$. Proceso cardinal bilobulado, compuesto por un par de lóbulos subparalelos en su parte posterior y divergentes hacia adelante. Los lóbulos están separados longitudinalmente por un surco muy pronunciado el cual presenta una baja y delgada cresta, en formas juveniles. Cada lóbulo en vista posterior presenta un surco ancho y superficial.

Campo muscular de los aductores profundamente excavado en el fondo de la valva, de contorno subromboidal a suboval, limitado posterolateralmente por las proyecciones de las bases de los braquióforos. Impresiones de músculos aductores anteriores y posteriores, poco diferenciadas; región posterior del campo muscular, dendrítica. Miofragma bien definido, extendido hasta el límite anterior del campo muscular. En especímenes juveniles, dicho miofragma está representado por una arista muy delgada, mientras que en estadios más gerónticos, se torna más ancho y robusto. Superficie interna de la valva, en especímenes juveniles, con reflejo de la ornamentación externa. En formas gerónticas, 
esta impresión queda restringida al borde periférico de la valva, estando el resto de la valva cubierto por las impresiones del sistema de canales del manto.

\section{Comparación}

Con respecto a la especie tipo del género, los especímenes descritos difieren en el menor tamaño de las valvas; mayor número de costillas; presencia de miofragma en la valva ventral; conformación del proceso cardinal y en el campo muscular dorsal bien diferenciado. De la especie I. iris, los especímenes de I. dominans n. sp. difieren en el mayor tamaño de las conchas, forma y número de las costillas. Con referencia a la especie $I$ elongata, I. dominans n. sp. difiere en el menor tamaño de las valvas y mayor número de costillas. Con respecto a la especie I. eodevonica, proveniente de las calizas de Koněprusy, del Praguiense de Bohemia, las formas descritas se diferencian en el menor tamaño de las valvas (25 a $40 \mathrm{~mm}$ de ancho en $I$. eodevonica), mayor número de costillas (7-9 costillas en $5 \mathrm{~mm}$ en $I$. eodevonica, mientras que $I$. dominans n. sp. posee 15-16 costillas en $5 \mathrm{~mm})$.

En relación a las especies descritas por Smith (1980) en el Devónico inferior (Lochkoviense) de las islas del Canadá Artico, I. dominans n. sp. se diferencia de $I$. johnsoni, en el contorno y tamaño de las valvas; posición del ancho máximo; forma del proceso cardinal y en la presencia de miofragma en la valva dorsal. Con respecto a la especie $I$. thorsteinssoni, la forma precordillerana $I$. dominans n. sp. se diferencia en el tamaño de las valvas, tipo de ornamentación, menor divergencia de las láminas dentales y conformación de los lóbulos del proceso cardinal.

El material aquí descrito fue comparado con formas del género Iridistrophia halladas en la secuencia devónica de la sierra de Perijá, Venezuela, destacándose la similitud que posee el material descrito con la especie I. dendritica. Sin embargo, la especie $I$. dendritica se diferencia en el mayor ángulo de divergencia de las láminas dentales y de las bases de los braquióforos; menor número de costillas por milímetro y mayor convexidad de la valva ventral. Uno de los caracteres más notorios -en la similitud de ambos grupos de especímene-- es el tipo de impresiones dendríticas en la region posterior del campo muscular dorsal. No obstante, es de destacar que el carácter dendrítico del campo muscular dorsal en las formas de Venezuela, no es un atributo exclusivo, ya que se presenta, con mayor o menor intensidad, en las diferentes especies, tanto de la Precordillera Argentina como de otras secuencias devónicas de Bolivia y Uruguay.

I. dominans n. sp. se diferencia de I. prima n. sp. en el contorno, mayor tamaño de las valvas y en el menor ángulo apical $\left(159^{\circ}\right.$ en $I$. prima). Internamente difiere en: el menor ángulo de divergencia de las láminas dentales ( $103^{\circ}$ en $I$. prima y $81^{\circ}$ en $I$. dominans), la mayor longitud de las mismas; en el mayor desarrollo de las impresiones musculares ventrales y menor ángulo de divergencia de los braquióforos.

El material descrito fue comparado con las especies del género Schellwienella referidas por Castellaro (1966) en la secuencia devónica de la Formación Talacasto. No obstante, es necesario destacar que para las formas asignadas a $S$. inca (d'Orbigny), S. sulivani (Morris y Sharpe) y $S$. tenuis (Morris y Sharpe), en las sucesiones devónicas de Matto Grosso e Islas Malvinas, se impone una revisión genérica, ya que corresponderian al género Iridistrophia. A pesar de ello, la forma más afín al material y que ha sido mencionada (Castellaro, op.cit.) para el Devónico de la Precordillera Argentina, correspondería a $S$. sulivani (procedente de las Islas Malvinas). Sin embargo, nuestros especímenes difieren en el menor desarrollo del campo muscular ventral (nunca alcanza las $2 / 3$ partes de la longitud como en $S$. sulivani), menor desarrollo de las fosetas dentales, menor tamaño de las valvas y menor número de costillas. S. inca difiere de I. dominans n. sp. en el contorno de las valvas, el mayor desarrollo del campo muscular ventral, forma del proceso cardinal y del miofragma dorsal.

\section{Iridistrophia aliciae n. $\mathrm{sp}$. Lám.I , figs. 30-38}

v. 1991 Iridistrophia sp. B, Herrera, 69-72, lám. 12, figs. 311.

Derivatio nominis: Del nombre femenino Alicia, en honor a la bióloga Alicia A. Paz, Universidad Nacional de Córdoba, Argentina.

Holotipo: Molde interno de valva ventral CEGH-UNC 2575 (Lám. I, fig. 32).

Paratipo: Molde interno de valva dorsal CEGH-UNC 2576 (Lám. I, fig.34).

Localidad tipo: Cerro del Fuerte, provincia de San Juan, Precordillera Argentina. Niveles superiores de la Formación Talacasto.

\section{Material}

10 moldes internos de valvas ventrales y 10 de valvas dorsales. Numerosos exteriores de ambas valvas.

\section{Distribución y edad}

Presente en la localidad de cerro del Fuerte, de edad Praguiense superior.

\section{Diagnosis}

Concha de tamaño mediano a grande, de contorno semicircular a semielíptico, (L/A de 0,82), con un ángulo apical promedio de $142^{\circ}$. Láminas dentales largas, Llám promedio de $5 \mathrm{~mm}$, divergentes según un ángulo de $82^{\circ}$. Campo muscular ventral grande, extendido un medio a dos tercios de la longitud valvar.

Medium to large size shell $(L / W$ mean ratio $=0.82)$, subelliptic outline, with a mean apical angle of $142^{\circ}$. Long dental plates, with a medium length of $5 \mathrm{~mm}$, diverge in a mean angle of $82^{\circ}$. The ventral muscular area is big and extended 2/3 of the valve length. 


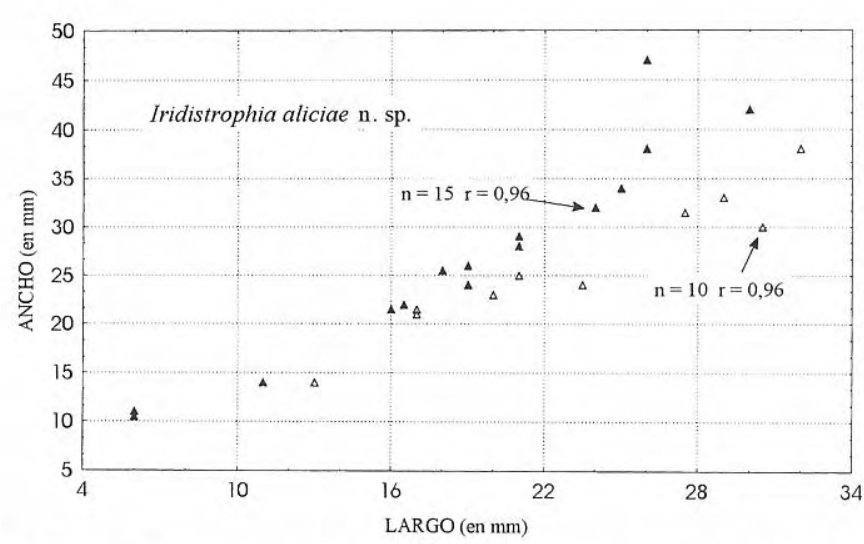

Figura 5. Diagrama de relación Largo/Ancho de la especie I. aliciae n. sp. $\Delta$ Valvas dorsales, $\Delta$ valvas ventrales.

\section{Descripción}

Concha de tamaño mediano a grande $(\mathbf{L}=23 \mathrm{~mm}, \mathbf{A}=26$ $\mathrm{mm}$ ), largo máximo observado, $30 \mathrm{~mm}$ (Fig. 5), de contorno semicircular a semielíptico. Perfil longitudinal convexoplano a levemente resupinado. Línea cardinal recta, ángulos cardinales ligeramente obtusos a rectos. Ancho máximo observado de $47 \mathrm{~mm}$. Valva ventral plana o moderadamente resupinada. Umbón ventral aguzado. Interárea ventral alta, un cuarto a un quinto de la longitud de la valva, de contorno subtriangular, netamente apsaclina, ángulo apical promedio de $142^{\circ}$ (variable entre $130^{\circ}-148^{\circ}$ ). Valva dorsal convexa, con la mayor convexidad localizada hacia la mitad de la longitud de la valva. Umbón pequeño y robusto. Interárea dorsal muy baja, aproximadamente una quinta parte de la ventral. Ornamentación constituida por costillas delgadas, en sección transversal subredondeadas, separadas por espacios intercostales anchos. El incremento en el número de las costillas es por intercalación y se cuentan en el borde anterior 6 en $2 \mathrm{~mm}$. Líneas de crecimiento muy marcadas en número de 4 a 5 en toda la superficie de la valva.

Interior ventral con dientes de tamaño mediano, subtriangulares, soportados por láminas dentales largas (largo promedio $5 \mathrm{~mm}$ ), gruesas y divergentes según un ángulo cercano a los $82^{\circ}$. En individuos gerónticos, las mismas están parcialmente obliteradas por depósitos secundarios. Campo muscular de contorno subtriangular, con margen anterior débilmente flabelado a difuso. Impresiones de los músculos diductores grandes, de extensión variable entre un medio y dos tercios de la longitud valvar. Miofragma angosto y elevado, dividiendo longitudinalmente al campo muscular. Crenulación periférica fuertemente impresa.

Interior dorsal con fosetas dentales grandes, subtriangulares, no soportadas por placas y subparalelas a la línea cardinal. Rebordes internos delgados limitan internamente a las fosetas. Braquióforos cortos, delgados y divergentes según un ángulo de $90^{\circ}$. Proceso cardinal bilobado y dirigido postero-ventralmente; ambos lóbulos están separados por un surco longitudinal angosto y profundo, el cual se corresponde, por debajo del mismo, con una pequeña cresta. Cada lóbulo, en su parte media, está recorrido por un surco longitudinal, el cual se profundiza y

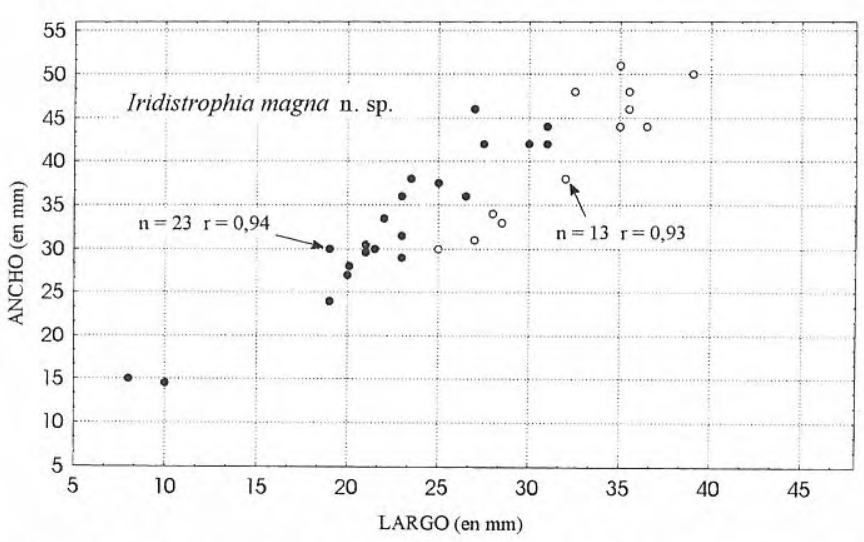

Figura 6. Diagrama de relación Largo/Ancho de la especie I. magna n. sp. - Valvas dorsales, o valvas ventrales.

ensancha en formas adultas, insinuándose un segundo surco muy pequeño en el margen externo de cada lóbulo. Miofragma angosto y superficial, poco diferenciado en la mayoría de los especímenes. Campo muscular escasamente definido. Superficie interna de la valva lisa o con reflejo de la ornamentación externa.

\section{Comparación}

Los especímenes asignados a $I$. aliciae n. sp. difieren de I. umbella (Barrande, 1848), en el mayor tamaño de las valvas, mayor número de costillas y menor cantidad de líneas concéntricas. De la especie I. iris (Barrande, 1879) se diferencia por su mayor tamaño (ancho máximo en I. iris: $27 \mathrm{~mm}$, ancho máximo en I. aliciae n. sp.: 45 $\mathrm{mm}$ ), contorno de las valvas, posición del ancho máximo y tipo de ornamentación. Con respecto a la especie $I$. elongata (Barrande, 1879), I. aliciae n. sp. difiere en el contorno de las valvas y tipo de ornamentación externa; los caracteres internos no pudieron ser comparados por cuanto el material original está representado por un exterior de valva ventral. De la especie I. eodevonica Havlíček, 1967, I.aliciae. n. sp. difiere en el tipo de ornamentación y en la presencia de láminas dentales más gruesas; caracteres internos de la valva dorsal, como proceso cardinal y campo muscular, no pudieron ser comparados pues los mismos son desconocidos en las formas de Bohemia.

Con respecto a la especie I. johnsoni Smith, 1980, proveniente del Devónico temprano (Lochkoviense) de las islas del Canadá Artico, I.aliciae n. sp. difiere en el tamaño de las valvas, menor número de costillas, mayor desarrollo de las láminas dentales y presencia de miofragma en la valva ventral. De la especie $I$. thorsteinssoni Smith, 1980, del Lochkoviense del Canadá Artico, los especímenes asignados a I.aliciae. n. sp. difieren en el mayor tamaño de las valvas, menor número de costillas, láminas dentales más gruesas y menos divergentes, y en la presencia de miofragma ventral.

I. aliciae $\mathrm{n}$. sp. se diferencia de I. prima n.sp. en la mayor longitud de la concha ( $\mathrm{L}$ promedio en I. prima $\mathrm{n}$. sp. es de 16,4 mm), en el campo muscular ventral, bien definido y dividido por un miofragma angosto y elevado 
en I. aliciae n. sp., mientras que en I. prima n. sp. el campo muscular ventral es indiferenciable. En relación a la valva dorsal, se diferencia por presentar un miofragma angosto y superficial, el cual en I. prima n. sp. es grueso y bien deferenciado, extendiéndose una sexta parte de la longitud valvar. Con respecto a I. dominans n. sp., se diferencia en el contorno de las valvas, el menor número de costillas por milímetro, mayor ángulo de divergencia de los braquióforos, la ausencia de placas soportando las fosetas dentales, en el menor desarrollo del surco entre los lóbulos del proceso y la mayor inclinación posteroventral del mismo; igualmente en el menor desarrollo del miofragma dorsal y en las impresiones del campo muscular dorsal.

\section{Iridistrophia magna $\mathrm{n}$. sp. Lám. I, figs. 39-42; Lám. II, figs. 1-18}

Derivatio nominis: Del latín magnus-a-um, grande, en alusión a su gran tamaño.

Holotipo: Molde interno de valva ventral, CORD-PZ 9353 (Lám. II, fig. 5).

Paratipo: Molde interno de valva dorsal, CORD-PZ 9354 (Lám. II, fig. 11).

Localidad tipo: Cordón de Agua del Peñón, provincia de San Juan, Precordillera Argentina. Niveles de canales superiores de la Formación Talacasto.

\section{Material}

Numerosos moldes externos e internos de ambas valvas: 25 interiores de valvas ventrales y 27 de valvas dorsales.

\section{Distribución y edad}

Secuencia de canales presentes en la faja oeste de la cuenca devónica, Formación Talacasto, cordón de Agua del Peñón - sierra de La Invernada, edad Emsiense superior?

\section{Diagnosis}

Concha de gran tamaño, de contorno semielíptico, relación L/A de 0,82. Interárea ventral alta, con ángulo apical promedio de $142^{\circ}$. Láminas dentales largas, Llám promedio $=8 \mathrm{~mm}$, largo máximo $12 \mathrm{~mm}$, gruesas en formas adultas y divergentes según un ángulo promedio de $84^{\circ}$. Proceso cardinal prominente, con lóbulos muy divergentes y dirigidos postero-ventralmente. Campo muscular grande y profundamente impreso.

Large size valve with subelliptic outline, $L / W$ mean ratio $=0.82$. The ventral interarea is high, with a mean apical angle of $142^{\circ}$. Long dental plates, mean legth is 8 $\mathrm{mm}$ and maximum legth is $12 \mathrm{~mm}$. They area thick in adult forms and diverge with a mean angle of $84^{\circ}$. Prominent cardinal process, with highly divergent lobes, posterio-ventrally directed. Big and deeply imprinted muscular area.

\section{Descripción}

Conchas de tamaño grande, más anchas que largas, $\mathbf{L}=$ $29 \mathrm{~mm} \mathrm{~A}=35 \mathrm{~mm}$, largo máximo observado $39 \mathrm{~mm}$. Perfil longitudinal convexo-plano a resupinado. Ancho máximo de la valva coincidente con la línea cardinal a ligeramente desplazado hacia delante; ancho máximo observado de 56 mm (Fig. 6). Valva ventral plana a levemente convexa en la región posterior, márgenes laterales redondeados, márgenes posteriores rectos, conformando un ángulo apical promedio de $142^{\circ}$ (variable entre $135^{\circ}-165^{\circ}$ ). Interárea ventral alta, apsaclina, aproximadamente una quinta a una sexta parte del largo valvar. Deltirio cubierto enteramente por un seudodeltidio. Valva dorsal uniformemente convexa. Interárea anaclina, muy baja, un tercio a un cuarto de la ventral. Placas quilidiales muy reducidas. Ornamentación constituida por costillas delgadas de sección transversal angulosa, con espacios intercostales levemente más redondeados. El aumento de las costillas es por intercalación; el número de costillas en 2 milímetros, hacia el margen anterior, es de 2-3.

Interior ventral con dientes pequeños y robustos, soportados por láminas dentales largas $(8 \mathrm{~mm})$, largo máximo observado de $12 \mathrm{~mm}$ y mínimo $6 \mathrm{~mm}$; divergentes en un ángulo que varía entre $68^{\circ}$ y $94^{\circ}$. Si bien el ángulo de divergencia de las láminas dentales sufre una cierta variación en los distintos estadios ontogenéticos, la mayor

\section{Lámina II}

1-18 Iridistrophia magna n. sp. 1, 2, molde interno dorsal y réplica en látex, CORD-PZ 9397 (x 0,8). 3, 4, moldes internos ventrales CORD-PZ 9398, 9399 (x 1). 5, 6, molde interno ventral y réplica en látex, Holotipo, CORD-PZ 9353 (x 0,8). 7 - 10, moldes internos ventrales, incompletos, CORD-PZ 9400, 9401, 9402, 9403 (x 1). 11, réplica látex interior dorsal, Paratipo, CORD-PZ 9354 (x 1). 12, 13, 17, réplica en látex de un interior dorsal, y molde interno dorsal del mismo ejemplar donde se observa detalle del campo muscular, en vistas dorsal y posterior, CORD-PZ 9404 (x 0,5). 14, réplica en látex de un interior dorsal CORD-PZ 9405 (x 1). 15, 16, 18, moldes internos dorsales CORD-PZ 9406, 9407, 9408 (x 0,5).

19-32 Eoschuchertella delicata n. sp. 19, 20, molde externo dorsal y réplica en látex, CORD-PZ 9409 (x 2) (x 2,5). 21, réplica en látex, exterior dorsal, CORD-PZ 9410 (x 2,5). 22, molde interno ventral, Holotipo, 9412 (x 2). 23, 24 moldes internos ventrales, CORD-PZ 9355, 9411 (x 2). 25 - 27, moldes internos dorsales CORD-PZ 9413, 9414, 9415 (x 3) (x 2) (x 1,5). 28, molde interno dorsal, Paratipo, CORD-PZ 9357 (x 2,5). 29, réplica en látex, interior ventral CORD-PZ 9416. 30, molde interno ventral CORD-PZ 9417 (x 3). 31, 32, molde interno y réplica en látex de varias valvas, incluido Paratipo (exterior ventral) CORD-PZ 9356 (x 2,5). 

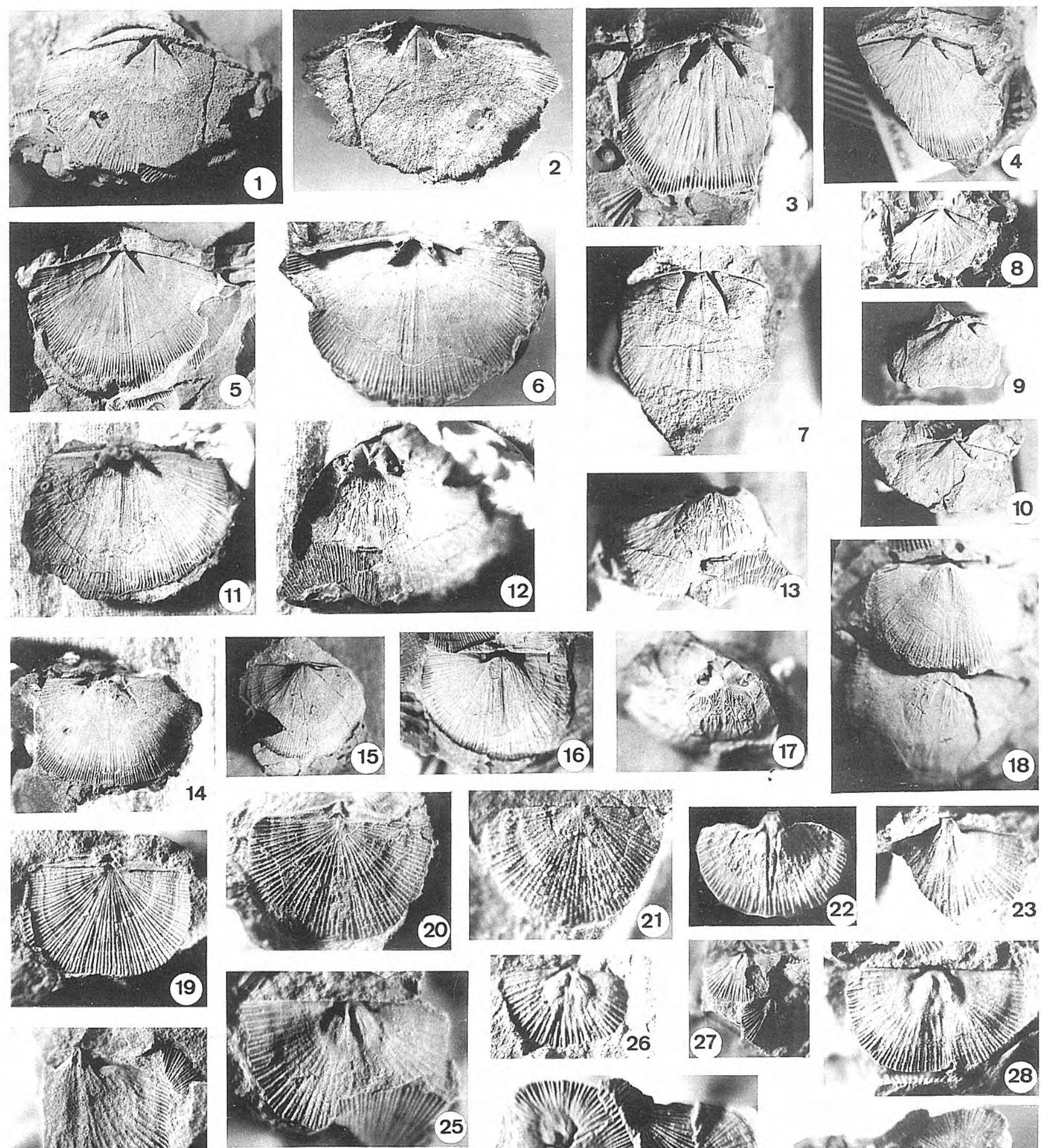

24
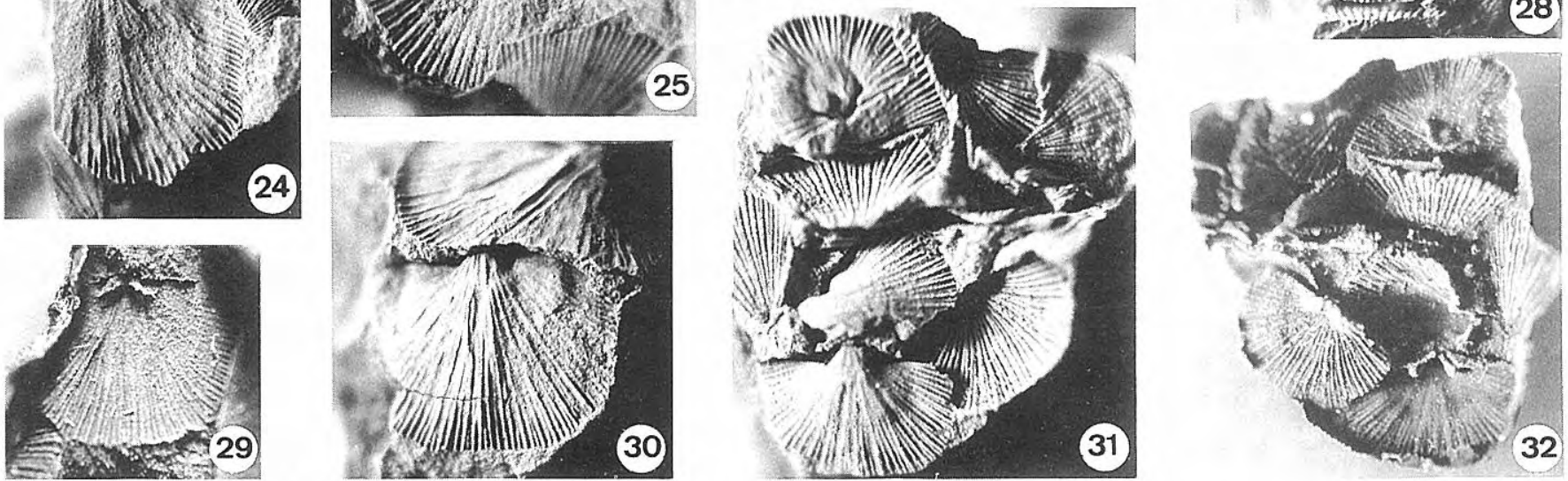

Revista Española de Paleontología, 13 (2), 1998 
modificación ocurre en longitud y espesor, tendiendo a ser en las formas adultas o gerónticas más espesas con extremos distales levemente convergentes.

Interior dorsal con proceso cardinal marcadamente bilobulado y divergente en vista anterior, prominente y dirigido posterolateralmente. Los lóbulos son largos, de contorno subtriangular y convergentes hacia el fondo de la valva, cada lóbulo presenta un surco longitudinal, en su parte media, que le otorga un aspecto cuadrilobulado. En formas adultas o gerónticas, este surco se ensancha, presentando numerosas estrías transversales y se genera un segundo surco longitudinal, más angosto. En posición mediana y debajo del surco que divide a ambos lóbulos del proceso, existe una cresta pequeña. Fosetas dentales profundas, divergentes y de contorno subtriangular, limitadas por rebordes internos gruesos y prominentes unidos hacia atrás con el proceso cardinal y culminando hacia delante en braquióforos grandes y robustos que divergen según un ángulo que varía alrededor de los $95^{\circ}$. Campo muscular bien impreso, en la mayoría de los ejemplares de contorno subromboidal, extendido generalmente hasta la mitad de la longitud valvar y dividido medianamente por un miofragma bajo y ancho. Superficie del campo muscular cubierta por numerosas impresiones dendríticas muy acentuadas. Borde anterolateral crenulado.

\section{Comparación}

En relación a las especies identificadas por Havlíček (1967) en el Devónico de Bohemia, I. umbella (Barrande, 1848) difiere de I. magna en el mayor número de costillas por milímetro (6 a 8 , en $5 \mathrm{~mm}$ ); mayor ángulo apical; menor ángulo de divergencia de las láminas dentales $\left(70^{\circ}-80^{\circ}\right.$ en $I$. umbella); en la ausencia de miofragma ventral y en el campo muscular dorsal (indiferenciable en I. umbella, mientras que en I. magna está fuertemente impreso). En relación a $I$. iris (Barrande, 1879) la especie I. magna se diferencia en el mayor tamaño y contorno de las valvas y en el tipo de ornamentación externa (en $I$. iris las costillas se ensanchan gradualmente hacia adelante, mientras que en I. magna el ancho de las mismas se mantiene constante). La ausencia de caracteres morfológicos internos en la descripción de Havlíček (op.cit.) imposibilita realizar una comparación más detallada. Con respecto a $I$. elongata (Barrande, 1879), la especie precordillerana difiere en la forma y número de costillas, puesto que en I. elongata las mismas son bajas y redondeadas, con 11 a 12 costillas en $5 \mathrm{~mm}$; al igual que en $I$. iris, el desconocimiento de los caracteres internos imposibilita realizar una comparación más certera. I. magna n. sp. difiere de la especie I. eodevonica Havlícek, 1967 en la ornamentación (las costillas son más numerosas en $I$. eodevonica, 7-9 en $5 \mathrm{~mm}$, mientras que I. magna posee 5-6 en $5 \mathrm{~mm}$ ). Asimismo, I. eodevonica difiere de $I$. magna en la ausencia de filae concéntricas y presencia de láminas dentales delgadas y campo muscular indiferenciado.

Con respecto a las especies de Iridistrophia reconocidas por Smith (1980) en el Devónico Inferior de las islas del Canadá Artico, I. johnsoni Smith, 1980 difiere de la nueva especie I. magna en: el contorno subcircular de las valvas, posición del ancho máximo ubicado en la mitad de la longitud valvar y en la disposición convexa de las costillas en los márgenes posterolaterales. Internamente, I. magna difiere en el mayor desarrollo del campo muscular dorsal y ventral, mientras que en I. johnsoni está poco definido. Respecto a la especie I. thorsteinssoni Smith, 1980, la especie de la Precordillera difiere en el mayor tamaño de las valvas y en el tipo de ornamentación (I. thorsteinssoni es más finamente costulada, con aumento del número de las costillas tanto por intercalación como por bifurcación, mientras que en I. magna el aumento es siempre por intercalación).

I. magna se diferencia de la especie $I$. dendritica Benedetto, 1984 (lám. 8, figs. 8-17; lám. 9, figs. 1-6), de la Formación Caño Grande, Emsiense Superior Eifeliense, de la sierra de Perijá (Venezuela), en el perfil longitudinal y tamaño de las valvas y en el tipo de ornamentación más finamente costulada en $I$. dendritica. Internamente difiere en el ángulo de divergencia tanto de las láminas dentales como de los braquióforos, los cuales, en $I$. dendritica, son cercanos a $120^{\circ}$, mientras que en $I$. magna $\mathrm{n}$. sp. son de $84^{\circ}$ y $95^{\circ}$, respectivamente.

Los especímenes identificados como Iridistrophia magna $\mathrm{n}$. sp. difieren de I. prima n. sp. en el contorno y mayor tamaño de las valvas, así como en el menor ángulo apical. Internamente, difiere en el mayor desarrollo de las láminas dentales y en el menor ángulo de divergencia de las mismas; así como en el mayor desarrollo del campo muscular ventral. Asimismo, I. magna se diferencia en la mayor inclinación postero-ventral y distinta configuración de los lóbulos del proceso cardinal y en el mayor desarrollo del campo muscular dorsal.

Con respecto a la especie $I$. dominans n. sp., I. magna n. sp. se diferencia externamente en el mayor tamaño y perfil longitudinal de las valvas y en el menor ángulo apical. Internamente la mayor diferencia radica en el desarrollo de las láminas dentales ( 7 a $8 \mathrm{~mm}$ en 1 . magna y 3-4 mm en I. dominans), en el mayor ángulo de divergencia de los braquióforos y en la forma del proceso cardinal.

De las especies reconocidas en el Devónico de la Precordillera, las formas que más se asemejan a $I$. magna son las de la localidad del cerro del Fuerte, I. aliciae n. sp., tanto por la forma de las valvas como por el ángulo apical, número de costillas y configuración del proceso cardinal. Sin embargo, I. magna nov. sp. difiere en la mayor longitud de las láminas dentales y en el mayor desarrollo del campo muscular y del miofragma dorsal.

Familia Areostrophiidae Manankov, 1979

Subfamilia Adectorhynchinae Henry and Gordon, 1985 Género Eoschuchertella Gratsianova, 1974

Especie tipo: Eoschuchertella popovi Gratsianova, 1974. 


\section{Eoschuchertella delicata n. sp. Lám. II, figs. 19-32}

Derivatio nominis: Del latín delicatus - $a-u m$, delicada, suave.

Holotipo: Molde interno de valva ventral, CORD-PZ 9412 (Lám. II, fig. 22).

Paratipos: Molde externo de valva ventral y molde interno de dorsal, CORD-PZ 9356, 9357 (Lám. II, figs. 28, 31).

Localidad tipo: Quebrada Zerina, cerro La Chilca, provincia de San Juan, Precordillera Argentina. Niveles superiores de la Formación Talacasto.

\section{Material}

11 moldes internos de valvas ventrales y 14 de valvas dorsales. Numerosos exteriores de ambas valvas.

\section{Distribución y edad}

Localidad de cerro La Chilca, quebrada Zerina Emsiense tardío.

\section{Diagnosis}

Conchas pequeñas, de contorno subrectangular y el ancho máximo coincidente con la línea cardinal. Ángulo apical variable alrededor de los $154^{\circ}$. Ornamentación constituida por 9 costillas en $2 \mathrm{~mm}$. Láminas dentales cortas y divergentes en un ángulo promedio de $77^{\circ}$. Campo muscular dorsal bien definido.

Small valves with rectangular outline, and the maximun width coincident with the cardinal line. Apical angle is variable ca. $154^{\circ}$. The ornamentation is constituted by 9 ridges in $2 \mathrm{~mm}$. Short and divergent dental plates with a mean angle of $77^{\circ}$. Dorsal muscular area well defined.

\section{Descripción}

Concha pequeña, de contorno subrectangular, más ancha que larga; relación L/A de 0,73 (Fig. 7). Ancho máximo coincidente con la línea cardinal, extremidades cardinales ligeramente agudas. Valva ventral plana a levemente convexa en la región posterior. Interárea plana, baja, con una altura aproximada a una quinta parte de la longitud valvar, apsaclina; deltirio cubierto por un seudodeltidio convexo. Márgenes posteriores de la valva conformando un ángulo apical que varía alrededor de $\operatorname{los} 153^{\circ}-154^{\circ}$. Valva dorsal levemente convexa, más acentuada en la región posterior de la valva. Interárea muy baja a inconspicua, con placas quilidiales muy reducidas. Costillas finas, triangulares en sección, con espacios intercostales más anchos y redondeados. Se incrementan en ambas valvas por intercalación, presentando 9 costillas en $2 \mathrm{~mm}$. Observándose dos a tres líneas de crecimiento muy marcadas y numerosas estrías concéntricas en los espacios intercostales.

Interior ventral con dientes pequeños, robustos y redondeados. Láminas dentales cortas, restringidas a la cavidad subumbonal, divergentes según un ángulo de $76^{\circ}$. Campo muscular indiferenciado. Superficie interna de la valva con reflejo de la ornamentación externa.

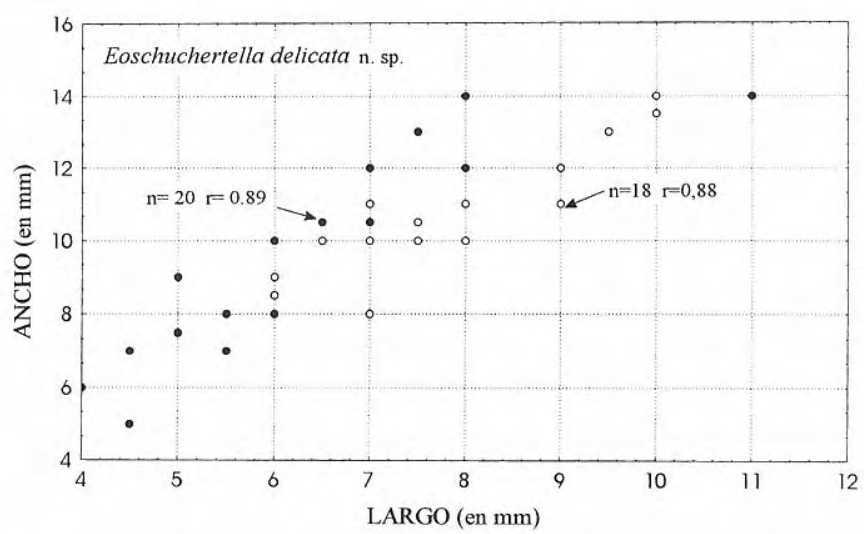

Figura 7. Diagrama de relación Largo/Ancho de la especie Eoschuchertella delicata n. sp. • Valvas dorsales, - valvas ventrales.

Interior dorsal con proceso cardinal bilobulado, bajo. Fosetas profundas y pequeñas, limitadas por rebordes internos que se fusionan posteriormente al proceso cardinal. Braquióforos divergentes en un ángulo promedio de $107^{\circ}$. Miofragma ancho en la región posterior, extendiéndose aproximadamente un cuarto de la longitud de la valva. En las formas más juveniles, el miofragma es ancho y bajo y se restringe a la parte posterior de la valva. Campo muscular de contorno subcircular y fuertemente excavado en el fondo de la valva, prolongándose más de la mitad de la longitud de la valva. No se distinguen las impresiones de los músculos aductores posteriores y anteriores. Superficie interna de la valva con reflejo de la ornamentación externa; en formas adultas se observan las impresiones de los canales del manto.

\section{Comparación}

Los especímenes de la Precordillera fueron asignados al género Eoschuchertella Gratsianova, 1974 tanto por la condición impuntuada de las valvas como por sus características internas: forma del proceso cardinal y braquióforos y ausencia o escaso desarrollo de las láminas dentales.

Los especímenes provenientes de la Formación Talacasto se diferencian de la especie tipo del género, $E$. popovi Gratsianova, 1974 (en Gratsianova, 1975, lám. 18, figs. 5-11) en el contorno y tamaño de las valvas y en el tipo de ornamentación.

De Eoschuchertella tuktui Jones, 1985 (en Jones y Smith, 1985, p. 421-425, lám. 1-12), E. delicata n. sp. se diferencia en el menor desarrollo del campo muscular ventral y ausencia del reborde limitante del mismo y en el menor ángulo apical.

De las especies de Eoschuchertella descritas por Brice (1988) en el Devónico de Ferques (Boulonnais, Francia), E. bouchardi (Rigaux, 1872) es una de las especies que más se asemeja a E. delicata n. sp. en el tamaño, contorno y valor del ángulo apical. Sin embargo, difiere en la posición del ancho máximo de la valva, inclinación de la interárea y en el mayor número de costillas. Con respecto a $E$. ferquensis Brice, 1988 , la especie $E$. delicata $\mathrm{n}$. sp. se diferencia en el contorno y menor tamaño de las valvas (25 a $42 \mathrm{~mm}$ de ancho en $E$. 


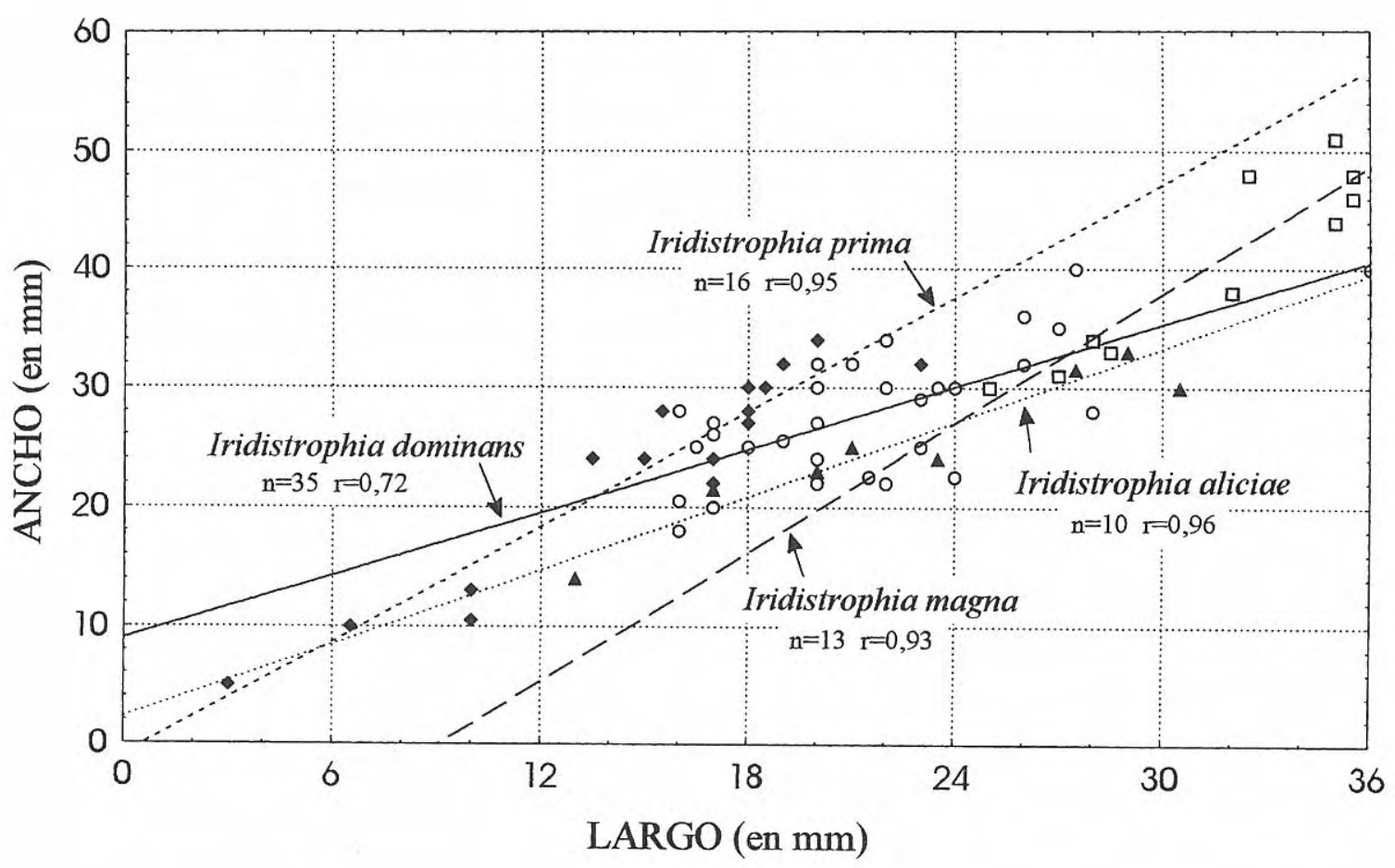

Figura 8. Diagrama integrado de la relación Largo/Ancho de todas las especies de Iridistrophia reconocidas en este trabajo. -I. prima n. sp., ${ }^{\circ}$ I. dominans n. sp., $\Delta$ I. aliciae n. sp., $\square$ I. magna n. sp.

ferquensis, mientras que en E. delicata n. sp. varía de 8 a $14 \mathrm{~mm}$ ); mayor ángulo apical y mayor número de costillas. Internamente se diferencian en el campo muscular ventral muy bien impreso en E. ferquensis.

En relación a Eoschuchertella? elegans (Rigaux, 1872), las formas aquí descritas se diferencian fundamentalmente en el contorno más transverso de las valvas (subcircular en E.? elegans), posición del ancho máximo de la valva -siempre ubicado en la mitad de la longitud valvar o por delante en E.? elegans- y en la disposición de las costillas (en E.? elegans éstas tienden a ser recurvadas hacia las extremidades cardinales, mientras que en E. delicata n. sp. las mismas son paralelas al borde posterior de la valva).

En relación a la forma de Eoschuchertella identificada por Smith (1980, pág. 44, lám. 13, figs. 22-35) en las islas del Canadá Ártico, la nueva especie E. delicata n. sp. difiere en el contorno menos transverso de la concha y posición del ancho máximo.

\section{VARIACIÓN DE LAS ESPECIES DEL GÉNERO Iridistrophia EN EL DEVÓNICO PRECORDILLERANO}

El análisis morfológico detallado de las diferentes especies del género Iridistrophia-presentes en la secuencia siliciclástica de la Formación Talacastopermitió efectuar un análisis de las variaciones interespecíficas que ocurren en las formas de Iridistrophia de la Precordillera argentina. Para tal fin, se consideraron diversos parámetros mensurables en la concha, tales como: largo (L), ancho (A), ángulo apical (Aa), ángulo de las láminas dentales (Alam), largo de las láminas dentales (Llam) y ángulo de los braquióforos $(\mathrm{Ab})$, entre otros (Tabla 1). Estos parámetros fueron considerados importantes para el estudio biométrico, ya que los mismos permiten diferenciar cada uno de los grupos de individuos hallados tanto en la base (Lochkoviense inferior) como en el techo (Praguiense

\begin{tabular}{|c|c|c|c|c|c|c|c|}
\hline & $\mathbf{L}(\mathrm{mm})$ & $\mathbf{A}(\mathrm{mm})$ & L/A & $\mathrm{Nc}(\mathrm{en} 3 \mathrm{~mm})$ & Aa & Llam (mm) & Alam \\
\hline I. prima $\mathrm{n} . \mathrm{sp}$. & 15 & 24 & 0,62 & $5-6$ & $159^{\circ}$ & 3 & $103^{\circ}$ \\
\hline I. dominans $\mathrm{n}$. sp. & 21,7 & 27,4 & 0,79 & 7 & $155^{\circ}$ & 3,4 & $81^{\circ}$ \\
\hline I. aliciae n. sp. & 23 & 26 & 0,82 & 6 & $142^{\circ}$ & 5 & $82^{\circ}$ \\
\hline I. magna $\mathrm{n} . \mathrm{sp}$. & 29 & 35 & 0,82 & $2-3$ & $142^{\circ}$ & 8 & $84^{\circ}$ \\
\hline
\end{tabular}

Tabla 1. Cuadro comparativo del promedio de los parámetros mensurables en las diferentes especies de Iridistrophia reconocidas en este trabajo. 


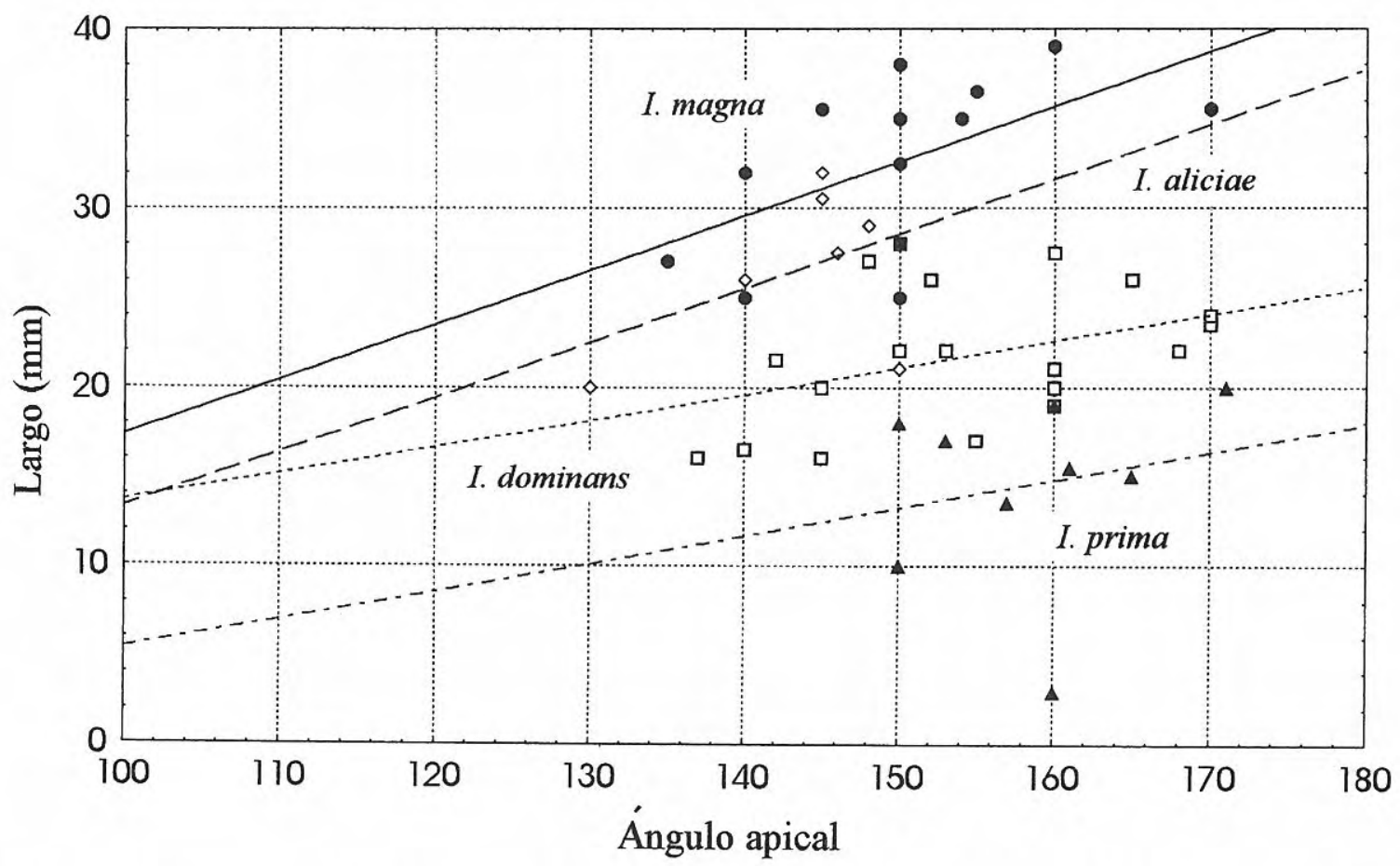

Figura 9. Diagrama representativo de la relación Largo/Ángulo apical de todas las especies de Iridistrophia, presentes en la Precordillera. $\Delta$ I. prima n. sp., $\square$ I. dominans n. sp., $\diamond$ I. aliciae n. sp., • I. magna n. sp.

superior - Emsiense inferior) de la Formación Talacasto.

Los principales aspectos en los caracteres morfológicos externos que marcan la variación específica de las formas presentes en la Precordillera, están relacionados con la progresiva disminución -en las formas jóvenes- del ángulo apical $\left(159^{\circ}\right.$ en $I$. prima a $142^{\circ}$ en $I$. magna) y el aumento del largo de la valva (14,9 mm en I. prima, 21,7 mm en I. dominans, $23 \mathrm{~mm}$ en $I$. aliciae y $29 \mathrm{~mm}$ en $I$. magna, todos valores promedios), lo cual está acompañado por una modificación del contorno de la concha y por un ligero desplazamiento hacia delante del ancho máximo. En la Figura 8 se ilustran las relaciones L/A de cada una de las especies reconocidas; en la misma se especificaron los coeficientes de correlación entre las variables estudiadas que muestran valores entre 0,72 y 0,96 , lo que indica una buena relación entre los parámetros considerados. Asimismo, en la Figura 9, puede observarse la variación existente entre las diferentes especies de la cuenca devónica de la Precordillera con relación al ángulo apical y a la longitud de la valva.

Entre los caracteres morfológicos internos de la valva ventral, la principal diferencia se encuentra en el progresivo incremento de la longitud de las láminas dentales. En I. prima (Lochkoviense inferior) las láminas tienen una longitud de $3 \mathrm{~mm}$, mientras que en I. magna (Emsiense inferior?) el valor promedio es de $8 \mathrm{~mm}$, llegando en algunos casos a 11 y $12 \mathrm{~mm}$. El ángulo de divergencia de las láminas decrece considerablemente desde la forma del Lochkoviense (I. prima, 103) a las especies del Praguiense superior - Emsiense inferior, en las cuales el ángulo de divergencia de las láminas oscila entre $81^{\circ}$ y $84^{\circ}$.
En la Figura 10 se muestra un cuadro comparativo de las variaciones horizontales (geográficas) y verticales (temporales) de las distintas formas de Iridistrophia reconocidas en la Formación Talacasto. Para la confección del mismo se tuvieron en cuenta los caracteres morfológicos de la valva ventral, tales como: ángulo apical, ángulo y longitud de las láminas dentales; en todos los casos se mantuvieron las relaciones largo y ancho -promedio- para cada una de las especies reconocidas. Como puede apreciarse en esta figura, las especies $I$. dominans e I. aliciae fueron referidas a la Biozona de Asociación C (Herrera, 1993, 1995b); sin embargo, I. aliciae correspondería a una especie evolutivamente más jóven que $I$. dominans y de la cual habría derivado la especie I. magna.

Con relación a los caracteres internos de la valva dorsal, existen transformaciones progresivas en las formas del Praguiense - Emsiense inferior, referidas tanto a la configuración y mayor inclinación póstero-ventral del proceso cardinal, como al incremento en superficie y en la impresión del campo muscular. Las formas más jóvenes, como I. magna, presentan un proceso cardinal con una fuerte inclinación postero-ventral y un campo muscular amplio, extendido aproximadamente la mitad de la longitud valvar y bien impreso. Asimismo, en $I$. magna el proceso cardinal presenta un segundo surco en cada lóbulo, paralelo al surco principal mediano, el cual se ubica hacia el margen externo de cada lóbulo. La presencia de este surco ya se encuentra insinuada en las formas adultas de $I$. aliciae. Otros caracteres, como el ángulo de divergencia de los braquióforos, no sufren una variación tan acentuada en las diferentes especies reconocidas. 


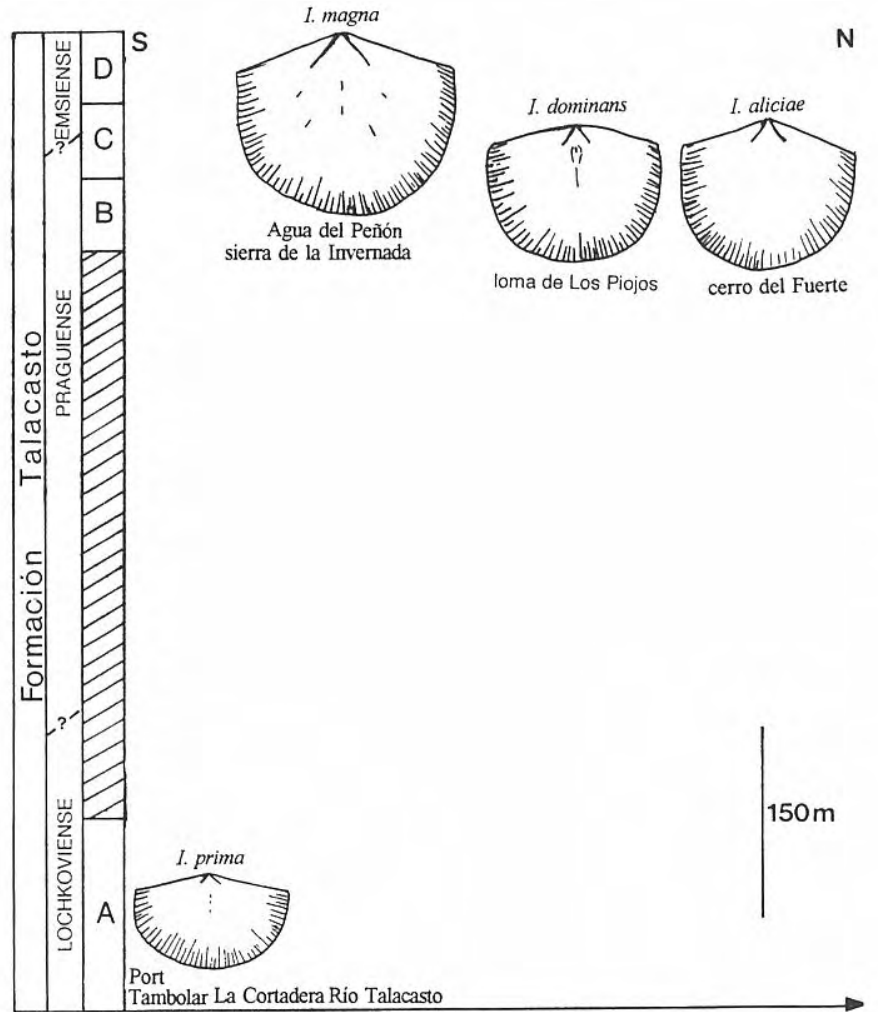

Figura 10. Variación horizontal (geográfica) y vertical (temporal) de las características morfológicas de la valva ventral (L, A, ángulo interárea, longitud y ángulo de divergencia de las láminas dentales), de las diferentes especies del género Iridistrophia en la Formación Talacasto. (A,B,C,D: Biozonas de Asociación, tomado de Herrera, 1991, 1995b y Giolitti, 1994).

\section{DISTRIBUCIÓN GEOGRÁFICA Y EDAD}

Es necesario destacar que la presencia de formas atribuibles a Iridistrophia en la cuenca de la Precordillera, amplía considerablemente la distribución geográfica de este género en las secuencias devónicas de Sudamérica, puesto que hasta el momento sólo se había reconocido su presencia en la sierra de Perijá, Venezuela (Benedetto, 1984).

Asimismo, es necesario señalar que las formas que siempre fueron asignadas al género Schuchertella en las secuencias devónicas de sudamérica, principalmente de Bolivia, Brasil (Paranaiba, Amazonas y Paraná), Uruguay, Islas Malvinas (Falkland) corresponderían, según el criterio de uno de los autores (Z.H), al género Iridistrophia. La reasignación taxonómica al género Iridistrophia del material que con anterioridad había sido atribuido a Schuchertella (Campanha y Mabessone, 1974; Carvalho, 1975; Isaacson, 1977, entre otros), se fundamenta en el estudio de ejemplares de la Formación Icla (cuenca devónica de Bolivia), de la Formación El Cordobés (Sur de la cuenca de Paraná, Uruguay) y en el análisis de los caracteres morfológicos que proporcionan las descripciones e ilustraciones, de distintos autores, en las publicaciones referidas a braquiópodos devónicos de Sudamérica.

El registro del género Iridistrophia, según los estudios realizados por $\mathrm{A}$. Williams y C.H.C Brunton en la revisión del Treatise (Brunton, com. epist.), estaría restringuido al "Silúrico superior (Ludloviense)Devónico Inferior (Lochkoviense), de Europa y China". Distribución en tiempo y espacio que no abarca las formas de Iridistrophia del Praguiense-Emsiense y menos aún las formas presentes en las secuencias de Sudamérica. Esto último podría aceptarse "en parte" por cuanto ciertas cuencas devónicas de Sudamérica han permanecido un tanto desconocidas y sin revisión de sus determinaciones taxonómicas, hasta comienzos de la década de los noventa. La distribución espacio-temporal, asignada por Brunton (com.epist.) para el género Iridistrophia, en la revisón del Treatise, genera numerosos interrogantes en relación con las formas de Iridistrophia del Praguiense y Emsiense de Europa, así como a las formas de este género reconocidas en América del Norte y del Sur.

\section{ASPECTOS PALEOBIOGEOGRÁFICOS}

Las cuencas devónicas de Bolivia, sur de Brasil, Uruguay, Malvinas y, principalmente, la Precordillera Argentina, han sido referidas y consideradas siempre, por numerosos geólogos y paleontólogos, como exclusivas del Dominio Malvinocáfrico, y, por consiguiente, relacionadas con aguas "frías".

Es a partir de la década de los setenta cuando en la Precordillera Argentina se menciona por primera vez la presencia de elementos pertenecientes al Dominio del Este Americano (Baldis 1975, Levy y Nullo, 1972). Trabajos posteriores, todos referidos a fauna de braquiópodos (Herrera, 1991, 1993, 1995 a, b; Racheboeuf y Herrera, 1994), han permitido obtener un panorama más amplio acerca de las afinidades de estas faunas y, por lo tanto, de sus relaciones paleobiogeográficas. En este sentido, la presencia del género Iridistrophia, junto con otros géneros reconocidos en la Precordillera y pertenecientes a dominios faunísticos tanto del Este Americano (Spinoplasia, Metaplasia, Coelospira, Meristella) como del Viejo Mundo (Boucotia, Sicoryncha, Trigonirhynchia) contribuyen a esclarecer las afinidades paleobiogeográficas de estas faunas. Asimismo, en la secuencia devónica de la Formación Talacasto están presentes chonetáceos (Chonostrophia, Plicanoplia y Anoplia) considerados típicos del Dominio del Este Americano.

La marcada influencia de elementos de afinidad tanto del Este Americano como del Viejo Mundo en la secuencia devónica de la Formación Talacasto, contribuye no sólo a "desmitificar" el origen exclusivamente Malvinocáfrico de las mismas, sino que plantea además la necesidad de dilucidar las vías de migración que hicieron posible el ingreso de estas poblaciones.

Determinar el origen de las faunas de braquiópodos devónicos de la Precordillera, así como de las cuencas 
vecinas (Bolivia, sur de Brasil, Uruguay, entre otras) resulta un problema, en la actualidad, de difícil resolución, principalmente fuera del ámbito precordillerano, por cuanto las restantes cuencas devónicas de Sudamérica (excluyendo Bolivia), consideradas típicamente Malvinocáfrico, no cuentan con estudios bioestratigráficos y taxonómicos recientes, que permitan hacer una evaluación pormenorizada de las diferentes formas halladas y su correcta distribución areal y temporal. Más aún, considerando que la secuencia devónica de la Formación Talacasto representa, hasta el momento, la única secuencia marina del intervalo LochkovienseEmsiense con abundante material fosilífero, tanto de braquiópodos como de trilobites y, en menor proporción de formas de tabulados y restos aislados de plantas. Un estudio más detallado sobre las relaciones paleobiogeográficas de la cuenca devónica de Argentina con las demás de Sudamérica, se encuentra en ejecución.

Por otra parte, es necesario señalar que existe, junto a los datos de la fauna de braquiópodos, nueva información sobre otras faunas que aportan más elementos en el estudio de los aspectos paleobiogeográficos. Así, en el trabajo de Vannier et al. (1995), sobre ostrácodos provenientes de los niveles superiores de la Formación Los Espejos (Lochkoviense) (localidad de cerro del Fuerte), dichos autores indican la influencia de elementos provenientes de America del Norte, como Thlipsurella, Phanasymmetria y Ranapeltis que aparecen en en Oklahoma y Tennesee. Asimismo, el trabajo efectuado por García-López y Fernández-Martínez (1995), referido a la presencia de Parastriatopora (en la sección de Portezuelo del Tambolar, Precordillera) forma conocida en Alaska, Siberia, Kazakstán, China, Australia, NE y SO de Europa y $\mathrm{N}$ de África, corresponde a formas de latitudes ecuatoriales y tropicales, fundamentalmente.

Todos los datos de la fauna de braquiópodos conducen a diferenciar la Precordillera Argentina, como una región biogeográfica de mezcla (Herrera, 1991, 1995a). Donde vía “corrientes cálidas con sentido NESO” (como las sugeridas por García-López y FernándezMartínez, 1995, basadas en Gnoli et al., 1990 y Sarmiento y García López, 1993) se podría explicar el ingreso de estos elementos "atípicos".

\section{AGRADECIMIENTOS}

Z.H. desea expresar su sincero agradecimiento a la Dra. Graciela Sarmiento (Universidad Complutense, España), al Dr. Patrick R. Racheboeuf (Université Claude Bernard Lyon I, Francia), Dr. Guillermo Albanesi (Universidad Nacional de Córdoba, Argentina), por la lectura del manuscrito. Al Dr. Howard Brunton (Natural History Museum) por sus útiles sugerencias. A los Drs. J. García Alcalde, C. Winkler Prins y M.L. Martinez Chacón, por sus útiles comentarios y sugerencias. Al Sr. Noël Podevigne (Université Claude Bernard-Lyon I) por realizar -con toda gentileza- las copias del material fotográfico. Para la realización del presente trabajo se contó con apoyo económico del proyecto de investigación $\mathrm{N}^{\circ} 1159 / 95$, subsidiado por el Consejo de
Investigaciones Científicas y Tecnológicas de la Provincia de Córdoba (CONICOR).

\section{BIBLIOGRAFÍA}

Baldis, B.A. 1975. Valoración de elementos faunísticos para una zonación y datación de edades en el Devónico inferior de la Precordillera Argentina. I Congreso Argentino de Paleontología y Bioestratigrafía, 1, 219-240.

Benedetto, J.L. 1984. Les brachiopodes dévoniens de la Sierra de Perijá (Venezuela). Systématique et implications paléogeographiques. Biostratigraphie $d u$ Paléozö̈que, 1, 1-191.

Brice, D. 1988. Brachiopodes du Dévonien de Ferques (Boulonnais - France). Biostratigraphie du Paléozoique, 7, 323-401.

Campanha, V.A. e Mabesoone, J.M. 1974. Paleoambiente e paleoecologia do membro Picos, formaçao Pimenteiras (Devoniano do Piaui). 28 Congresso Brasileiro de Geologia, Sociedade Brasileira de Geologia, 2, 220-325.

Carvalho, R.G. de. 1975. Braquiópodes devonianos da bacia Amazônica: Orthida, Strophomenida, Spiriferida e Terebratulida. Boletim do Museu Paraense Emílio Goeldi, 21, 1-36.

Castellaro, H.A. 1966. Guía palentológica Argentina. Parte I. Paleozoico, secc. IV Faunas devónicas. Publicación Especial de CONICET, $164 \mathrm{pp}$.

Clarke, J.M. 1913. Fosseis Devonianos do Parana. Servicio Geológico e Mineralógico do Brasil, 1, $353 \mathrm{pp}$.

García-López, S. and Fernádez-Martínez, E. 1995. The genus Parastriatopora Sokolov, 1949 (Tabulata) in the Lower Devonian of Argentine: palaeogeographic implications. Geobios, 28, 175-183.

Giolitti, J.A. 1994. Estratigrafía de la secuencia devónica (Formación Talacasto) en el área del cerro La Chilca sierra La Trampa, Precordillera de San Juan. Trabajo de Licenciatura inédito, Universidad Nacional de Córdoba, $66 \mathrm{pp}$.

Gnoli, M., Kriz, J., Leone F., Olivieri, R., Serpagli, E. and Storch, P. 1990. Litostratigraphic units and biostratigraphy of the Silurian and early Devonian of Southwest Sardinia. Bolletino della Società Paleontologica Italiana, 29, 11-23.

Gratsianova, R.T. 1975. Early and middle Devonian Brachiopods of the Altai-Sayan region. Strophomenidina. Nauka, 105 pp.

Havlícek, V. 1967. Brachiopoda of the Suborder Strophomenidina in Czechoslovakia. Ustredního Ustavu Geologického, 33, 235 pp.

Herrera, Z.A. 1991. Taxonomía, bioestratigrafía y paleobiogeografía de los braquiópodos de la Formación Talacasto (Devónico) de la Precordillera Argentina. Tesis Doctoral inédita, Universidad Nacional de Córdoba, 283 pp.

Herrera, Z.A. 1993. Nuevas precisiones sobre la edad de la Formación Talacasto (Precordillera Argentina) en base a su fauna de braquiópodos. XII Congreso Geológico Argentino y II Congreso de Exploración de Hidrocarburos, 2, 289-295. 
Herrera, Z.A. 1995a. The first Notanopliid Brachiopod from the South American Devonian sequence. Geobios, 28, 337-342.

Herrera, Z.A. 1995b. Lower Devonian chonetoidean brachiopods from the Argentine Precordillera. In: Four Contributions to the Study of Chonetoidean Brachiopods (Ed. P.R. Racheboeuf). Documents des Laboratoires Géologie Lyon, 136, 101-148.

Herrera, Z.A. y Racheboeuf, P.R. (1997). Afinidades paleobiogeográficas de la fauna de braquiópodos devónicos de la Precordillera Argentina. XIII Jornadas de Paleontología, Fósiles de Galicia y V Reunión Internacional del Proyecto 351 del PICG, A Coruña, 1997 (Eds. A. Grandal d'Anglade, J.C. Gutiérrez-Marco y L. Santos Fidalgo), 83-86.

Isaacson, P.E. 1977. Devonian stratigraphy and brachiopod paleontology of Bolivia. Part. A: Orthida and Strophomenida. Palaeontographica A, 155 (5-6), 133 193.

Jones, B. and Smith, G.P. 1985. Taxonomy and distribution of brachiopods in the Devonian Eids Formation of southwest Ellesmere Island, Artic Canada. Journal of Paleontology, 59, 418-437.

Levy, R. y Nullo, F. 1972. Chonetididae devónicos de Argentina 1. Chonostrophia. Ameghiniana, 11, 138-144.

Racheboeuf, P.R. and Herrera, Z.A. 1994. On some new Malvinokaffric Silurian and Devonian chonetacean brachiopods, and reclassification of others. Neues
Jahrbuch für Geologie und Paläontologie, 9, 541-560.

Salas, M.J., 1995. Estudio Taxonómico y Bioestratigráfico de la Fauna de Braquiópodos Devónicos en el área del Mogote La Cortadera (Sierra de La Deheza), Precordillera de San Juan. Trabajo de Licenciatura inédito, Universidad Nacional de Córdoba, 80 pp.

Sarmiento, G. y García López, S. 1993. Síntesis sobre las faunas de conodontos del Paleozoico Inferior de IberoAmérica y de la Península Ibérica (1958-1992). Revista Española de Paleontología, 8, 191-205.

Smith, R.E. 1980. Lower Devonian (Lochkovian) biostratigraphy and brachiopod faunas from the Canadian Artic Islands. Geological Survey of Canada Bulletin, 308, 79 pp.

Vannier, J., Racheboeuf, P.R., and Benedetto, J.L. 1995. Silurian-Early Devonian ostracodes from South America (Argentine, Bolivia): preliminary investigations. Journal of Paleontology, 69, 752-772.

Volkheimer, W. 1962. Nuevos hallazgos de Paleozoico marino en la Precordillera de San Juan. Revista de la Asociación Geológica Argentina, 17 (1-2), 97-104.

Williams, A. and Brunton, C.H.C. 1993. Role of shell structure in the classification of the Orthotetidine brachiopods. Palaeontology, 36, 934-966.

Williams, A., Carlson, S., Brunton, C. H. C, Holmer, L. and Popov, L. 1996. A supra-ordinal classification of the Brachiopoda. Philosophical Transactions of the Royal Society of London, 351, 1171-1193. 